NBER WORKING PAPER SERIES

\title{
ECB POLICIES INVOLVING GOVERNMENT BOND PURCHASES: IMPACT AND CHANNELS
}

\author{
Arvind Krishnamurthy \\ Stefan Nagel \\ Annette Vissing-Jorgensen \\ Working Paper 23985 \\ http://www.nber.org/papers/w23985 \\ NATIONAL BUREAU OF ECONOMIC RESEARCH \\ 1050 Massachusetts Avenue \\ Cambridge, MA 02138 \\ November 2017
}

We are grateful for comments from Alex Edmans, Jacob Goldfield, Bob Hall, Ricardo Reis, Massimo Rostagno, Bernd Schwaab, Paul Soderlind, Frank Smets, an anonymous referee and seminar and conference participants at the Copenhagen Business School, University of Michigan, Goldman Sachs, the European Finance Association Meeting, and the American Finance Association Meeting. This research was supported by a grant from the Global Markets Institute at Goldman Sachs. Any opinions, findings, conclusions, or recommendations expressed in this paper are those of the authors and do not necessarily reflect the views of Goldman Sachs or the Global Markets Institute. The views expressed herein are those of the authors and do not necessarily reflect the views of the National Bureau of Economic Research.

At least one co-author has disclosed a financial relationship of potential relevance for this research. Further information is available online at http://www.nber.org/papers/w23985.ack

NBER working papers are circulated for discussion and comment purposes. They have not been peer-reviewed or been subject to the review by the NBER Board of Directors that accompanies official NBER publications.

(C) 2017 by Arvind Krishnamurthy, Stefan Nagel, and Annette Vissing-Jorgensen. All rights reserved. Short sections of text, not to exceed two paragraphs, may be quoted without explicit permission provided that full credit, including $\odot$ notice, is given to the source. 
ECB Policies Involving Government Bond Purchases: Impact and Channels

Arvind Krishnamurthy, Stefan Nagel, and Annette Vissing-Jorgensen

NBER Working Paper No. 23985

November 2017

JEL No. E4,F45,G01,G18

\begin{abstract}
$\underline{\text { ABSTRACT }}$
We evaluate the effects of three ECB policies (the Securities Markets Programme, the Outright Monetary Transactions, and the Long-Term Refinancing Operations) on government bond yields. We use a novel Kalman-filter augmented event-study approach and yields on euro-denominated sovereign bonds, dollar-denominated sovereign bonds, corporate bonds, and corporate CDS rates to understand the channels through which policies reduced sovereign bond yields. On average across Italy, Spain and Portugal, considering both the Securities Markets Programme and the Outright Monetary Transactions, yields fall considerably. Decomposing this fall, default risk accounts for $37 \%$ of the reduction in yields, reduced redenomination risk for $13 \%$, and reduced market segmentation effects for $50 \%$. Stock price increases in distressed and core countries suggest that these policies also had beneficial macro-spillovers.

Arvind Krishnamurthy

Stanford Graduate School of Business

Stanford University

655 Knight Way

Stanford, CA 94305

and NBER

akris@stanford.edu

Stefan Nagel

University of Chicago

Booth School of Business

5807 South Woodlawn Avenue

Chicago, IL 60637

and NBER

stefan.nagel@chicagobooth.edu

Annette Vissing-Jorgensen

Haas School of Business

University of California, Berkeley

545 Student Services Building, \#1900

Berkeley, CA 94720

and NBER

vissing@haas.berkeley.edu
\end{abstract}




\section{Introduction}

During the most intense periods of the European financial crisis, Greece, Ireland, Italy, Portugal and Spain (the "GIIPS" countries) saw large increases in their government bond yields. Figure 1 graphs 2-year yields for GIIPS government bonds from 2010 onward. Italian and Spanish yields peak around $7 \%$ in the fall of 2011, while Portuguese and Irish bonds peak around $20 \%$. Greek 2-year yields rise above $200 \%$ prior to the Greek default in early 2012. In response, the ECB introduced programs aimed at lowering government bond yields on the presumption that such a reduction would have beneficial macroeconomic spillovers. The ECB programs included direct purchases of government debt (the Securities Markets Programme, SMP), conditional commitments to purchase government debt (the Outright Monetary Transactions, OMT), and 3year loans to banks which banks partly used to buy government debt (the Long-Term Refinancing Operations, LTROs). The objective of our paper is to assess these programs and shed light on the economic mechanisms through which the programs may have worked. Did they succeed in lowering government bond yields and improving the macroeconomic outlook? What are the channels through which ECB policies worked to reduce bond yields?

As with many unconventional central bank operations in recent years, little is known about the effects of these policies. The ECB has publicly stated that these policies reduce redenomination risk, i.e., the risk that the Eurozone might break up and countries redenominate domestic debt into new domestic currencies, and financial market "dysfunctionality," i.e., segmentation- and illiquidity-induced pricing anomalies. ${ }^{1}$ However, the relative importance of these channels is unknown and there are likely to be additional channels. Most importantly, the ECB's policies may have reduced the default risk component of GIIPS sovereign yields. A reduction in the default risk component could arise from the perception that the ECB might step in as a lender of last resort, or from the effects that conditions attached to these programs might have on GIIPS fiscal policies. If a policy is counter-productive, it could even result in a rise in the default risk component. Furthermore, traditional monetary policy channels through the default-free yield curve may play a role, too. In this paper, we provide quantitative estimates of five components of sovereign bond yields: an expectations hypothesis component, a euro-rate term premium, a default risk premium, a redenomination risk premium and sovereign bond market segmentation. We uncover the effects of ECB policies by asking how they impact each of these components.

\footnotetext{
${ }^{1}$ As examples, see the speeches of ECB's Executive Board Members Benoît Cœuré (September 3, 2013, http://www.ecb.europa.eu/press/key/date/2013/html/sp130902.en.html ) who emphasizes redenomination risk when discussing the OMT, and José Manuel González-Páramo (November 4, 2011

http://www.ecb.europa.eu/press/key/date/2011/html/sp111104 1.en.html ) who emphasizes financial market dysfunctionality when discussing the SMP.
} 
Disentangling these channels is valuable both for policy-making and academic research. For assessing policy, our empirical tests are informative about the joint hypothesis that a particular problem (e.g., redenomination risk concerns) exists, and that a given ECB program had an effect on this problem. Furthermore, understanding the channels can help to guide better policy. For example, if the main concern is redenomination risk, then actions to strengthen the Eurozone's commitment to the euro as opposed to purchases of sovereign bonds or liquidity injections to banks are likely to more directly address the risk. Such actions may involve both the monetary and fiscal authorities. On the other hand, if the main problem is market segmentation and illiquidity, then bond purchases as well as actions to improve the plumbing of the asset markets, such as enhancing trading platforms and repo market infrastructure can help address the problem. Finally, our channel decomposition is valuable for the theoretical literature in international finance on the determinants of sovereign bond yields (see Aguiar and Amador, 2014). This literature understands sovereign bonds yields almost exclusively through the lens of the default risk channel. The Euro crisis has brought to fore concerns regarding redenomination risk. Redenomination has similarities and differences with sovereign default. Lenders suffer losses in both a default as well redenomination event. But, relative to outright default, redenomination has a direct impact on private borrowers in the defaulting country, as it reduces these borrowers' Euro debt obligations. We provide estimates of redenomination risk which may be helpful in guiding theory. We also highlight that market segmentation can be an important factor in sovereign bond yields. While the finance literature has understood that segmentation can play an important role in many asset markets (see Darrell Duffie's (2010) presidential address to the American Finance Association), models of sovereign debt largely set aside such frictions.

We first document via a standard event-study that the SMP and OMT led to large reductions in GIIPS sovereign bond yield. The effects are biggest at the 2-year maturity with reductions around 200 basis points (bp) for Italy and Spain, 500bp for Portugal and Ireland, and more than $1,000 \mathrm{bp}$ for Greece. The LTROs had generally small effects on sovereign yields, with the largest (but still modest) effects of around 50bp seen for Spain. It is important to note that these event study estimates of yield changes are likely to capture only part of the overall effect of policies on yields given that the probability of policies being put in place was unlikely to be zero even before our first event date and may have increased between event dates.

The main contribution of our analysis is then to tease out the channels through which ECB policies affected interest rates. For data reasons this part of the analysis focuses on Italy, Spain and Portugal, although we also present some results for Greece around the SMP. We decompose euro-denominated government bond yields into two components that are common across all countries using the euro (an expectations hypothesis component and a euro-rate 
term premium) and three components that are country-specific (a default risk premium, a redenomination risk premium and sovereign bond market segmentation).

The country-specific components are not directly observable. To overcome this challenge we use information from a collection of asset prices that are differentially exposed to these components. Our identification relies on two basic observations. First, foreign-law sovereign bonds denominated in US dollars cannot be redenominated through domestic law changes and (after adjusting by the US dollar swap rate of similar duration) should only capture the default risk premium component of the sovereign bond yield. Second, redenomination into a new currency should affect all securities issued in a given country under the country's local law equally. In other words, the yields of euro-denominated local-law sovereign bonds and eurodenominated local-law corporate bonds (or loans) of the same duration should be affected equally by the risk of redenomination. Therefore, we can use data for corporations to identify the redenomination component of sovereign euro-denominated bond yields. The details of the implementation of these basic ideas differ between Italy on the one hand and Spain and Portugal on the other due to the fact that credit default swap contracts for G7-countries do not cover losses from redenomination whereas those for non-G7 countries do.

We estimate the components using a Kalman filter to account for measurement error in the asset prices used as well as the fact that some of the asset prices we use are based on less frequently traded assets for which shocks may have delayed effects on prices. The Kalman filter handles such asynchronous response to shocks by expanding the state vector to include lags of the latent components.

We then conduct an event-study on the extracted default risk premium, redenomination risk premium and sovereign bond market segmentation components. Doing an event study on components extracted using Kalman filtering is to our knowledge novel. Beyond the specifics of our study, we think that the Kalman-filter augmented event-study methodology can be fruitfully applied to other questions in finance.

Somewhat surprisingly and in contrast to the work on quantitative easing in the U.S. (see Krishnamurthy and Vissing-Jorgensen, 2011), we find that changes to the expectations hypothesis and euro-rate term premium yield component were of little importance for the policies studies here. Instead, the default risk premium and sovereign bond segmentation effect appear to have been the dominant channels through which the SMP and the OMT affected sovereign bond yields of Italy and Spain. Redenomination risk may have been present at times and it may have been a third policy channel for the SMP and OMT in the case of Spain and Portugal, but not for Italy. To give a sense of magnitudes, focusing on our first identification scheme (labeled (i) in Table 6) and the effects working via the country-specific channels, default risk accounts for $30 \%$ of the fall in yields across SMP and OMT for Italy. Segmentation accounts 
for the other $70 \%$. For Spain, the numbers are $42 \%$ (default risk), 15\% (redenomination risk) and $43 \%$ (segmentation). For Portugal, the numbers are $40 \%$ (default risk), $24 \%$ (redenomination risk) and 36\% (segmentation).

For the LTROs, we find that their effect on Spanish bond yields worked almost entirely via the sovereign segmentation channel. We show that the more substantial impact of the LTROs on Spanish sovereign yields than on Italian and Portuguese sovereign yields is consistent with Spanish banks purchasing a larger fraction of outstanding sovereign debt in the months following the introduction of the LTROs.

To assess whether ECB policies had broader macroeconomic impact than their impacts on sovereign bond yields, we document how stock returns reacted around the announcements. We find large positive impacts of the SMP and especially the OMT on stock returns, both for GIIPS countries and for core euro-zone countries, with the LTROs again having smaller effects. On average across European Union markets, stock prices rose about $13 \%$ in response to the OMT and 4\% in response to the SMP. Importantly, large stock market effects of the OMT and to a lesser extent the SMP are present even for non-financial stocks (for which gains on sovereign bond yields are not a potential driver of stock returns), suggesting broad macroeconomic impacts of these policies. We perform some simple calculations based on the market value changes of bonds and in stocks to argue that the benefit/cost ratio of the SMP and OMT is likely to be large, with benefits around $€ 1$ trillion and an upper bound of the cost to core country taxpayers of $€ 275$ billion. Our calculation may be conservative because it ignores key benefits such as market value changes for non-publicly traded firms, along with wage gains via reduced economic contraction.

Our paper contributes to a recent literature that has started to analyze the effects of ECB interventions on yields. However, existing research does not comprehensively assess the channels through which interventions affect bond yields, which is a central element of our paper.

Eser and Schwaab (2013) find that the SMP lowered yields on periphery bonds. Using internal ECB data on bond purchases under the SMP, they document large changes in bond yields upon purchase (i.e. distinct from the announcement effects we focus on here). Szczerbowicz (2015) use an event study methodology around ECB interventions and find that the SMP and OMT lowered covered bond spreads and periphery sovereign yields, while the main effects of the 3year LTRO were on money market spreads and covered bond spreads. Falagiarda and Reitz (2015) study the surprise information content of many ECB communications throughout the crisis and find that they generally reduced the spread between Italian and German sovereign yields. 
Other recent work focuses on the individual components of sovereign yield spreads related to solvency factors, redenomination risk, and market segmentation, but there is no other work that aims to disentangle these different factors. Di Cesare et al. (2012) use a model with fiscal and macroeconomic factors to argue that periphery sovereign bond yields during the height of the crisis were far above what can be explained by these fundamental factors. Based on several indicators, including the sovereign bond - CDS basis, they suggest that redenomination risk is substantial in the fall of 2011 whereas our analysis indicates that redenomination risk in the fall of 2011 may not have been as large as the sovereign bond-CDS basis suggested. De Pooter et al. (2012) use bond yields and CDS to study the effects of SMP purchases within a search-model framework. Their estimates suggest that the SMP affected bond yields primarily through a (partly temporary) reduction in the illiquidity premium in yields. Corradin and RodriguezMoreno (2013) observe that USD-denominated eurozone sovereign bonds -- including those of several core countries as well as Spain and Italy -- traded at substantially higher yields than EUR-denominated bonds of the same issuer during the 2008-12 period and that the SMP and three-year LTRO programs contributed to a widening of the spread. They attribute the spread to the collateral and capital requirement benefits of EUR-denominated bonds whereas we also emphasize the importance of the ECB focusing its purchases on euro-denominated bonds. Trebesch and Zettelmeyer (2014) back out the ECB's purchases of Greek bonds in the SMP in 2010. They find that the ECB targeted bonds with high yields and the higher the amount purchased of a particular bond by the ECB, the higher the drop in yields in that instrument, while bonds that were not purchased by the ECB saw an increase, rather than a decrease in yields, indicating market segmentation effects.

The most recent papers in this literature have begun to assess the extent to which the 3-year LTROs affected bank lending to the private sector. Carpinelli and Crosignani (2015) estimate that the 3-year LTROs increased bank lending to firms in Italy by a modest 2 percent. This effect is the joint result of the 3-year LTROs and an Italian government scheme which allowed banks to pay a fee to the government to get a guarantee on part of their assets, thus enabling these assets to be pledged as collateral with the ECB. The effect on bank lending is small in economic terms and relative to the amount of Italian bank borrowing in the 3-year LTROs which amounted to $7.9 \%$ of the value of bank assets. Consistent with this, Italian bank holdings of government bonds increase by between $4 \%$ and $9 \%$ (across various types of banks) as a percent of bank assets from November 2011 to March 2012. Garcia-Posada and Marchetti (2016) document the effect of the 3-year LTROs on bank lending by Spanish banks to the non-financial private sector. The 3-year LTROs are found to increase annual credit growth by about 1 percentage point. The effect is again small in economic terms and relative to the amount of Spanish bank borrowing in the 3-year LTROs which was about $9 \%$ of the value of bank balance sheets across banks in their sample. Andrade, Cahn, Fraisse, and Mesonnier (2015) focus on 
France and find that the EUR 153 billion total LTRO take-up for the banks in their sample let them to increase credit supply to the private sector by about 15 billion, again suggesting that only a small fraction of LTRO borrowings were lent out. Focusing on Portugal, Crosignani, Fariae-Castro and Fonseca (2015) show that net borrowing by Portuguese banks from the ECB went up substantially at the second 3-year LTRO allotment and that there is a strong positive relation in the cross-section of banks between bank purchases of Portuguese government bonds leading up to this allotment and the amount borrowed at the allotment. This is evidence that banks purchased bonds in order to engage in an ECB carry trade via the 3-year LTROs, pledging these bonds as collateral for ECB loans at lower rates than the expected return on the bonds. The fact that a large fraction of the 3-year LTRO borrowing was used to purchase government bonds was counter to the ECB's stated objective of using these operations to support bank lending. The ECB's subsequent LTROs, the targeted longer-term refinancing operations (TLTROs), tie bank borrowing from the ECB to bank lending to the private sector.

The rest of the paper is organized as follows. Section II provides a brief description of the ECB programs that we analyze. In Section III, we lay out the yield decomposition that underlies our empirical approach and discuss our identification strategy. Section IV presents the results. Section $\mathrm{V}$ provides some evidence on the potential macroeconomic impact of the policies. We conclude in Section VI.

\section{Description of ECB Programs}

\section{A. Securities Market Programme}

On May 10, 2010, the ECB introduced the Securities Markets Programme (SMP) whereby the ECB directly purchased government debt of distressed countries. ${ }^{2}$ ECB announcements did not indicate planned amounts of purchases. ECB total holdings under the SMP are graphed in Figure 2. Up to July 2011, the purchases resulted in holdings of around EUR 75 billion of securities. It is our understanding that during this first phase of the program only bonds of Greece, Ireland, and Portugal were purchased. On August 7, 2011, the ECB expanded the program. The second round of purchases included Italy and Spain. ECB holdings peaked at EUR 219.5 billion in February of 2012. ${ }^{3}$ Table 1 Panel A details the distribution of purchases, by country and maturity, as of December 2012. Italy and Spain represent the largest amount of purchases.

\footnotetext{
${ }^{2}$ While the program announcement stated that purchases may include private debt securities only government securities have been purchased.

${ }^{3}$ The SMP program was officially terminated on September 6, 2012, with the initiation of the Outright Monetary Transactions program (OMT).
} 
The average maturity of the holdings as of that time was around 4 years. Since purchases were made from May 2010-February 2012, with Italy and Spain purchases commencing in August 2011, the average maturity at purchase was up to 2.6 years higher for Portugal, Ireland and Greece and up to 1.4 years higher for Italy and Spain. This implies that the average maturity of ECB purchases was fairly comparable to the average maturity of debt outstanding (for example, OECD statistics report that the average term to maturity of government debt in 2010 was 7.2 years for Italy, 6.6 years for Spain, 5.8 year for Portugal, 5.9 years for Ireland, and 7.1 years for Greece). ${ }^{4}$

In terms of the ECB's motivation for the SMP, the ECB's press release on May 10, 2010 stated (our emphasis added in italics):

"In view of the current exceptional circumstances prevailing in the market, the Governing Council decided [....] to conduct interventions in the euro area public and private debt securities markets (Securities Markets Programme) to ensure depth and liquidity in those market segments which are dysfunctional. The objective of this programme is to address the malfunctioning of securities markets and restore an appropriate monetary policy transmission mechanism."

The Aug 7, 2011 release stated:

"The Governing Council of the European Central Bank (ECB) welcomes the announcements made by the governments of Italy and Spain concerning new measures and reforms in the areas of fiscal and structural policies. [....] It is on the basis of the above assessments that the ECB will actively implement its Securities Markets Programme. This programme has been designed to help restoring a better transmission of our monetary policy decisions - taking account of dysfunctional market segments and therefore to ensure price stability in the euro area."

In both cases, we note the ECB's reference to dysfunctional and illiquid market segments. We will study whether the government bond markets of the GIIPS countries were affected by segmentation/limits-to-arbitrage effects. We focus on May 10, 2010 and August 7, 2011 as the event dates for the SMP.

\section{B. Outright Monetary Transactions}

\footnotetext{
${ }^{4}$ See http://stats.oecd.org/Index.aspx?DatasetCode=GOV DEBT
} 
On September 6, 2012, the ECB introduced the Outright Monetary Transactions (OMT) program. The program has two key elements. First, under the OMT, the ECB can purchase government bonds of a given country, focusing on maturities between 1 and 3 years, and with no ex-ante quantitative limits. Second, a country has to apply for the OMT in which case it will also have to undertake a set of fiscal adjustments. That is, the program involved conditionality. As of today, no bonds have been purchased under the OMT program.

While the program was announced officially on September 6, 2012, there were earlier indications regarding the likelihood of such a program. On July 26, 2012, ECB President Mario Draghi stated at a conference that "within our mandate, the ECB is ready to do whatever it takes to preserve the euro. And believe me, it will be enough." Furthermore, the introductory statement of the ECB to the August 2, 2012 press conference stated:

"The Governing Council, within its mandate to maintain price stability over the medium term and in observance of its independence in determining monetary policy, may undertake outright open market operations of a size adequate to reach its objective. [...] Furthermore, the Governing Council may consider undertaking further non-standard monetary policy measures according to what is required to repair monetary policy transmission. Over the coming weeks, we will design the appropriate modalities for such policy measures."

In our event study of the OMT, we focus on these three dates, i.e. July 26, August 2 and September 6 of 2012.

The OMT was motivated by perceived redenomination risk associated with the breakup of the Euro. For example, on December 6, 2012, Draghi stated:

"We said that the main aim of the OMT is to remove tail risk to overcome monetary and financial fragmentation of the euro area that would stem from a redenomination risk."

We will study whether redenomination risk was an important factor in the dynamics of the bond yields of GIIPS countries.

\section{3-Year Long-Term Refinancing Operations}

On December 8, 2011, the ECB announced two 3-year Long-Term Refinancing Operations (LTROs). The operations were an extension of the ECB's main lending to banks, the main refinancing operation (MRO), to 3 years. Under the LTROs, like the MRO, banks received loans against a variety of collateral, subject to a collateral-specific haircut schedule. The loans were 
at a floating interest rate, tied to the ECB's policy rate. The lending was full allotment, meaning that banks did not face quantity limits on their borrowings.

The press release from the ECB stated:

"The Governing Council of the European Central Bank (ECB) has today decided on additional enhanced credit support measures to support bank lending and liquidity in the euro area money market. In particular, the Governing Council has decided to conduct two longer-term refinancing operations (LTROs) with a maturity of 36 months and the option of early repayment after one year."

Because the interest rate on the LTROs was floating at the MRO rate, the difference between the LTROs and the regular MRO was actually quite subtle. Rolling over weekly MRO funding over 3 years produced the same interest rate cost as a 3-year LTRO loan. One potential advantage of the LTROs is that they alleviated concerns that the ECB could revert at some point to a fixed-quantity variable-rate allotment policy that restricts funding quantities. The LTROs were similar to a firm commitment to provide a certain quantity of funding over a 3-year period. In any case, the take-up was substantial, and so banks must have perceived some benefit from taking out LTRO loans compared with rolling over MRO funding. The first allotment date for the LTROs was December 21, 2011. On this date, EUR 489.2 billion was borrowed by banks, from the ECB. The second allotment date was February 29, 2012, when EUR 529.5 billion was borrowed by banks. A substantial share of this borrowing volume was substitution from other ECB borrowing facilities. Across all ECB MRO, 3-month LTRO, 12-month LTRO, and 3-year LTRO facilities, the net increase in borrowing was EUR210.0 billion the week of the first allotment and EUR 310.6 billion in the week of the second allotment. ${ }^{5}$

News prior to December 8, 2011 suggested the possibility of an action by the ECB. For example, the Financial Times on November 24, 2011 reported in a headline that the "ECB eyes longerterm loans for banks," although the article did not point to a specific ECB statement that allows us to pin down a prior event date. The clearest prior announcement from the ECB was on December 1, 2011, when Draghi spoke to the European Parliament and said that "we are aware of the scarcity of eligible collateral" [for banks] and suggested that the "the most important thing for the ECB is to repair the credit channel." The Financial Times reported on December 1, 2011 ("Draghi hints at eurozone aid plan") that markets interpreted the Draghi speech to indicate an expansion of the SMP or a three-year LTRO.

Since we are interested in the impact of direct ECB government bond purchases or indirect purchases by banks induced by ECB lending, Table 1 Panel B provides estimates of the amounts

\footnotetext{
${ }^{5}$ https://www.ecb.europa.eu/mopo/pdf/mb201203en_box3.pdf?08c66bbcc045b15e9ae0e7038518274d
} 
of sovereign bonds purchased by banks using 3-year LTRO money, see column (2). The table is based on data from the Bruegel database of sovereign bond holdings. Comparing resident bank holdings of own-country sovereign bonds at the end of the second quarter of 2012 to holdings at the end of the third quarter of 2011 (pre-LTRO) shows that resident banks increased their holdings by EUR 86 billion for Italy, EUR 66 billion for Spain, EUR 5 billion for Portugal, and EUR 4 billion for Ireland, whereas Greek banks reduced their holdings of own-country sovereign bonds. These increases in resident bank holdings may not all have been induced by LTRO borrowing, but provide an indication of the magnitudes involved. As a percentage of the outstanding debt, the resident banks' purchases of domestic sovereign bonds over the period from 2011:Q3 to 2012:Q2 were much larger in Spain than in the other countries (about 10 percent of bonds outstanding for Spain, about 5 percent for Italy and Ireland, and about 2 percent for Portugal).

The use of LTRO funds to purchase sovereign debt was not the main objective of the policy (which as stated was focused on increasing bank lending) but it may have been a secondary motive. For example, French President Sarkozy stated that the LTRO "means that each state can turn to its banks, which will have liquidity at their disposal" (Financial Times Alphaville, December 15, 2011). The quantities stated above indicate that whether intended or not, the LTROs led to substantial financial sector purchases of sovereign bonds.

In our event study we focus on December 1 and December 8 of 2011 as LTRO event dates. Conclusions do not change materially if we add the two allotment dates. ${ }^{6}$

\section{Channels for Policy Impact on Government Yields: Identification}

Our main objective is to study the effect of ECB policies on sovereign bond yields, and to understand the channels through which these effects operate. We first describe how we decompose the overall yield changes into several economically interpretable components.

\section{A. Channels}

Consider the yield on a Euro-denominated government bond issued by country $c$ with remaining term to maturity $T$ :

\footnotetext{
${ }^{6}$ We do not include the LTRO allotment dates since effects on those dates would reflect news about the state of the banking sector in addition to news about the impact of the LTROs
} 


$$
\begin{gathered}
r_{T}^{c}=\frac{1}{T} \int_{0}^{T} E\left[i_{t}\right] d t+\text { TermPremium }_{T} \\
+ \text { DefRiskPremium } \\
T
\end{gathered}
$$

We have decomposed this bond yield into several components. The first and second components (top line) are not dependent on the identity of the country, $c$. Denote by $i_{t}$ the overnight interest rate at time $t$ on a safe and liquid bond, such as the overnight EONIA rate. Then the first component is the expectations hypothesis component of bond yields. Announcements regarding ECB government bond purchases may be taken as a signal of a more accommodative stance of the ECB and hence a signal reducing the future path of the policy rate. This effect has been important for the US quantitative easing programs, as explained in Krishnamurthy and Vissing-Jorgensen (2011). The second component reflects a term (or duration risk) premium associated with the bond. Since longer term bonds have interest rate risk, they likely carry a term premium. If the ECB programs affect macroeconomic outcomes and thus alter macroeconomic risk, they may affect duration risk premia and hence lower longer term rates (i.e. reduce TermPremium $_{T}$ in eq. 1 ). Note that both the signaling and duration risk channels are broad channels in that they will lower not only GIIPS government bond yields but also yields on core-country bonds and EONIA interest rate swaps. We do not separately identify the duration and signaling channels (they appear small in any case), and instead measure these channels, in sum, by using changes in the Euro swap rate (EONIA OIS swaps):

$$
S_{T}=\frac{1}{T} \int_{0}^{T} E\left[i_{t}\right] d t+\text { TermPremium }_{T}
$$

The next three components (second line) are country specific. The third component, DefRiskPremium $T_{T}^{c}$, reflects the premium for default risk. This premium in bond pricing models (see Duffie and Singleton, 1999) is driven by the likelihood of default, the loss given default, and the economic market-price-of risk associated with the default states. Our empirical approach will not disentangle these pieces separately, and hence we refer to the term only as a default risk premium. If ECB policies are viewed as signals that in the event of a sovereign nearing default, fiscal transfers will be made from core countries to the affected countries, then, the policies lower bond yields because they increase the expected repayments of bond-holders.

Another way that bond yields may be high is through redenomination risk. If bond holders worry that rather than (or in addition to) default on obligations, the government will choose to exit the Euro and redenominate its debt into a local currency at a depreciated exchange rate, then they will require a redenomination premium. The component, RedRiskPremium ${ }_{T}^{c}$, reflects the likelihood of redenomination, the depreciated value of the currency if 
redenominated, and the economic price-of-risk associated with the redenomination states. We refer to this term as a redenomination risk premium. For the same reasons that ECB policies may be perceived to reduce default risk, they could also lower risk that a country abandons the Euro in an attempt to regain monetary and fiscal flexibility.

The last component of the bond yield arises from segmentation (including illiquidity) frictions. If investors differ in their valuation of a bond and some investors are constrained from participating in the market, either because they are not active in the market for that bond or because they face portfolio constraints, then the market price will reflect the valuation of a subset of the investor population and bond yields will reflect a segmentation factor compared with the frictionless case. For example, if local investors are relatively optimistic, or if they see benefits to holding local bonds above and beyond the bonds' cash-flow -- say if the bonds are accepted as collateral at the ECB or they receive special regulatory treatment -- then they are willing to hold bonds at relatively high prices. If other investors, whose valuation is lower, reduce their holdings to zero, but face constraints in taking a short position, the yield on the bond will include a component Segmentation ${ }_{T}^{c}<0$. Alternatively, if some high-valuation investors drop out of the market -- say because of funding constraints -- bonds will have to be held by low valuation investors, leading to Segmentation ${ }_{T}^{c}>0$ and high bond yields. Note that the key assumption here is segmentation. If there are no segmentation frictions, then the bonds will be priced via the usual pricing kernel that applies to all assets, and the particular demands of some investors are irrelevant. Thus a key restriction for this component to be present is that there are limits to arbitrage as in Gromb and Vayanos (2002). There is ample evidence of the presence of segmentation frictions in a variety of asset markets. Mitchell et. al. (2002) and Lamont and Thaler (2003) present evidence from the equity market that the market value of a subsidiary can sometimes exceed the market value of a parent company. Greenwood and Vayanos (2010) describe the effect on long-term UK bonds of a change in regulation that led to an increased valuation of long-term bonds by UK pension funds. Ivashina et. al. (2015) describe the effects of a demand for dollar funding by European banks on covered interest parity. In all of these cases, a segmentation friction prevents a large set of investors from trading in the relevant market and undoing the demand effects of a subset of investors. Segmentation ${ }_{T}^{c}$ summarizes these demand effects, that because of segmentation frictions, affect bond yields. If markets are segmented, then ECB purchases of sovereign bonds will increase the price of these bonds causing Segmentation ${ }_{T}^{c}$ to fall and potentially even become negative. This occurs, for example, if the purchases are absorbed by a small number of market participants with limited capital.

These components are not independent. For example, expectations about the future path of interest rates and inflation may affect solvency, and hence default and redenomination risk. Rising yields due to redenomination concerns can also raise the risk of default and vice versa. In 
terms of eq. (1), if any of the other four terms on the right-hand side are reduced, this will endogenously lead to a reduction in DefRiskPremium $T_{T}^{c}$ and RedRiskPremium $T_{T}^{c}$. Related, the default and redenomination risk components have a self-reinforcing element that arises from the two-way feedback between interest rates and these risks. If lenders place a high probability on sovereign default or redenomination, they will require high interest rates, which will adversely affect the sovereigns' fiscal position and reinforce the default and redenomination fears. For example, in Cole and Kehoe (2000), the government rolls over short-term debt. If an investor fear that other investors will not rollover their debt, then they raise the interest rate they charge on debt, which in turn makes default more likely. We will not separately measure exogenous and endogenous default and redenomination risks. It is likely that both have played a part in the effects of ECB interventions.

\section{B. Identification and Estimation of Yield Components using Kalman Filtering}

The default risk premium, redenomination risk premium and segmentation components are not directly observable, posing a challenge for the estimation. The signaling and duration risk component of yields as directly observable through swap rates. Bond yields, net of Euro swap rates, are then the sum of the three remaining unobserved components: the default risk premium, the redenomination risk premium and segmentation. We treat these three components as latent variables that we uncover through a Kalman filter approach by jointly using the information in yields on euro-denominated and dollar-denominated government bonds, along with various corporate bond yields and credit-default swap (CDS) rates within a state-space model. We implement this approach for the three countries (Italy, Spain, and Portugal) for which we have sufficient data on dollar-denominated bond yields.

The Kalman filter helps us address another issue. Some of the securities we employ are illiquid, creating two measurement problems. First, with illiquidity, an observed price is equal to a true underlying price plus a measurement error (think of the error as capturing the impact of bid-ask spreads). Second, the prices of infrequently traded securities may only react with a lag to policy announcements. These two considerations imply that a standard event study could lead to biased estimates of the relative size of the policy channels.

We first lay out the Kalman filter accounting only for measurement error. In the next section, we augment the Kalman filter to account for the lagged impact of state variables on observables. 
Collect the observed yields and CDS rates in a vector $y_{t}$ with the domestic sovereign (swap-rate adjusted) bond yield as the first element and denote the state vector of the latent components as $x_{t}$. We assume that $x_{t}$ follows a (restricted and heteroscedastic) first-order wartar autoregression

$$
x_{t}=a+F x_{t-1}+u_{t}, \quad u_{t}=Q_{t}^{1 / 2} \varepsilon_{t}
$$

where $F$ is a diagonal matrix, $\varepsilon_{t}$ is a vector of mutually uncorrelated standard normal disturbances, and $Q_{t}=Q y_{1, t-1}$, i.e., conditional variances and covariances are proportional to the domestic bond yield, akin to a square-root process. This captures the tendency of shocks to sovereign bond yields to have higher volatility when yield spreads over swap rates are higher. ${ }^{7}$ The matrix $Q$ is unrestricted. The observed yields and CDS rates are linear combinations of the latent components plus heteroscedastic measurement error

$$
y_{t}=H x_{t}+w_{t}, \quad w_{t}=V_{t}^{1 / 2} \eta_{t}
$$

where $H$ is a known matrix, $\eta_{t}$ is a vector of mutually uncorrelated standard normal disturbances, and $V_{t}=V y_{1, t-1}$ with diagonal $V$. The Kalman filter and smoother allows us to use the observed $y_{t}$ to extract the unobserved $x_{t}$. We will then analyze how these underlying components react on policy dates.

Identification is made through the choice of $H$. In Table 2, Panel A we present the basic idea behind our identification. The table presents the matrix $H$ with element $(i, j)$ corresponding to observed asset price $-i$ (an element of the vector $y$ ) and latent component $-j$ (an element of the vector $x$ ). We start from two simple observations. First, foreign-law sovereign bonds denominated in US dollars cannot be redenominated through domestic law changes and (after adjusting by the US dollar swap rate of similar duration) should only capture the default risk premium component of the sovereign bond yield. Second, redenomination into a new currency should affect all securities issued in a given country under the country's local law equally. In other words, the yield of euro-denominated local-law sovereign bonds and euro-denominated local-law corporate bonds (or loans) of the same duration should be affected equally by the risk of redenomination. Therefore, we can use data for corporate bonds to identify the redenomination component of sovereign euro-denominated bond yields. For this to work well, the corporate bonds should be issued by relatively safe non-financial companies for which default risk is low and not closely tied to the default risk of the sovereign (as would be the case

\footnotetext{
${ }^{7}$ See, for example, Feldhütter and Lando (2008) for a related approach. While they use the lagged value of the unobserved components to model the covariance matrix, we use the lagged bond yield. This has the advantage that we use an observable variable (which is required under the assumptions of the Kalman filter). Also, in our setting, the segmentation components can be negative, which implies that it would not make sense to assume that their conditional variances depend on their own component lags.
} 
for banks). With the redenomination risk premium component identified from corporate bonds/loans, and the default risk premium component identified from dollar-denominated sovereign bonds, we can then identify the segmentation component of the yield on sovereign euro-denominated bonds as the remaining country-specific component of this yield. The Kalman filter also takes into account measurement error in the observables (see eq. 3 ) but the intuition behind identification does not change when accounting for measurement error, or lagged price adjustment.

Our identification assumes that domestic law and foreign law sovereign bonds have the same default risk premium. Reinhart and Rogoff (2011) show that in the post WWII period up to 2010 there is no clear pattern in terms of whether foreign debt or domestic debt holders do better in terms of incidence of default. More recently, in the Greek default the same loss was imposed on local and foreign bonds, although some holders of foreign-law debt who did not participate in the restructuring were paid in full (Zettelmeyer, Trebesch and Gulati, 2013).

A related question is whether it would be better to use sovereign CDS to measure the default risk premium rather than dollar-denominated bonds. We decide against this for two reasons. First, it is possible that sovereign CDS rates are an underestimate of default risk to the extent that market participants believe that the CDS may not be triggered in all "default" events. A Goldman Sachs note on Nov. 8 2012, Garzarelli (2012), raises this issue stating that "The extra compensation embedded in government bond spreads (relative to CDS) could reflect the possibility of an FX redenomination, and that of a debt restructuring which would not trigger CDS. Separating these two sources of risk is non-trivial." In the period leading up to the Greek restructuring, there was considerable uncertainty around whether or not the restructuring would trigger CDS payouts (it ultimately did in March 2012). For example, on October 27, 2011 the ISDA determined that the European Union's agreement with banks for a "voluntary" 50 percent write down on their Greek bond holdings would be unlikely to trigger CDS payments. The news changed CDS rates and bond yields in a manner that is consistent with shifts in the likelihood of CDS payouts. ${ }^{8}$ A second problem with using sovereign CDS rates is that the CDS rates may share a segmentation component with the sovereign bonds, which in particular reacts to ECB purchases. For example, suppose an ECB announcement made investors think that the ECB would always intervene to keep the yield spread (to swaps) on 2-year eurodenominated Spanish government debt at two percentage points below what it would be without intervention. This would affect a rational investor's willingness to pay for CDS protection. Even if the true default risk did not change, the fact that the investor could always sell the bond to the ECB at an inflated price means that the investor faces less effective default

\footnotetext{
${ }^{8}$ The 5-year CDS changes on October 27, 2012 are -50 bps (Italy), -65 bps (Spain), -195 bps (Portugal), and -95 bps (Ireland). Moreover these changes are larger in magnitude than changes in 5-year bond yields of these countries, suggesting changes in the likelihood of CDS payouts.
} 
risk, and hence is less willing to pay for CDS protection. Sovereign CDS rates will thus be distorted in the same direction as sovereign bond yields, but it is difficult to assess the relative magnitudes of the distortions.

\section{Baseline implementation for Italy}

We use non-financial corporate bonds and CDS to identify the redenomination risk premium. ${ }^{9}$ The precise way this is done differs between Italy on the one hand and Spain and Portugal one the other, due to differences in the way CDS payouts are affected by currency redenomination in these countries, and due differences in the availability of data on local-law eurodenominated corporate bonds and foreign-law dollar-denominated corporate bonds.

The ISDA Master Agreement that governs CDS contracts explicitly states that for G7 countries such as Italy, CDS contracts do not cover losses from redenomination risk. ${ }^{10}$ By contrast, for Spain and Portugal that are not G7 countries, CDS contracts would be presumed to cover losses from redenomination. Industry research letters confirm that this is the common perception in the market. For example, Credit Suisse (2010) states that "by definition [of being a G-7 member] Italy, ..., can re-denominate its government debt out of Euros into a new currency without triggering a restructuring, whereas Spain cannot (except in the extremely unlikely event it can keep a AAA rating through the process)".

For Italy, since CDS contracts only cover default risk, they can be used in conjunction with corporate bond yields to identify redenomination risk. We compare the corporate CDS rate to the yield on a local-law euro-denominated bond issued by the same corporation to identify redenomination risk: If the (swap-adjusted) euro-denominated bond yield is substantially above the CDS rate, this would be an indication of high redenomination risk. Our redenomination risk measure thus is equal to a corporate bond yield minus the swap rate minus the corporate CDS rate. In finance, this construction is known as the (negative of the) CDS-bond basis. Our

\footnotetext{
${ }^{9}$ The conceptually simplest approach to measuring redenomination risk from corporate bonds would be to use the yield spread between euro- and dollar-denominated corporate bonds. However, most European corporate bonds are issued in the Eurobond market, denominated in euros and issued under foreign law (i.e. not the law of the country of the bond issuing corporation). There are only a small number of non-financial corporate eurodenominated bonds issued under local law and also only a small number of corporate bonds denominated in dollars or other foreign currencies. Therefore, in our baseline implementation, we combine various corporate bond yields with information from corporate CDS rates in order to measure the redenomination component of bonds yields for a given country.

10 CDS contracts must pay if there is "any change in the currency or composition of any payment of interest or principal to any currency which is not a Permitted Currency. "Permitted currency" means (1) the legal tender of any Group of 7 country, or (2) the legal tender of any country which has a local currency long-term debt rating of either Aaa or higher" [ISDA Master Agreement]
} 
baseline implementation for Italy is presented in Table 2 Panel B. This is the same as Table 2 Panel A except for providing detail on exactly how the corporate data are used to identify the redenomination risk premium.

We use ENI, a large energy company and one of the safest non-financial firms in Italy, as the corporation for measuring redenomination risk. It is well known that the CDS-bond basis can deviate from zero even in the absence of redenomination risk, see e.g. Bai and Collin-Dufresne (2011). They find that during the US financial crisis the CDS-bond basis was substantially negative, around -200 bps for investment-grade firms and as low as -600 bps for junk-rated firms. This indicates that even absent redenomination risk, the basis, particularly for less safe firms, can be substantial. These authors also show that the basis, in the cross-section, correlates with measures of the transaction costs that impede arbitrage, such as funding costs, haircuts, and measures of counterparty risk. These findings suggest that any differential behavior of bond yields and CDS is partially a reflection of market segmentation. By using a safe non-financial firm such as ENI, we minimize the problem that our redenomination measure is affected by other components of the CDS-bond basis. Below we will consider an alternative approach that does not rely on using a CDS-bond basis to identify the redenomination risk premium.

We assume that the yield of domestic ENI bonds does not load on the domestic sovereign segmentation component (Table 2 Panel B). ENI's domestic bond issues are large and fairly liquid and they should not be much affected by factors that could drive segmentation in the domestic sovereign bond market, like the preferential treatment of sovereign debt in banks' risk weighting for regulatory capital requirements. Most importantly, the SMP and OMT focus on euro-denominated sovereign bonds and thus likely directly affect the segmentation component for sovereign bonds, but not any segmentation components for corporate bonds. As for the LTROs, they likely implied purchases of sovereign bonds and financial sector bonds, but are unlikely to directly have led to substantial purchases of non-financial corporate bonds. ${ }^{11}$ Hence, we assume that the swap-adjusted yield on ENI debt is affected by an ENI-specific default component and by redenomination risk (in the event of redenomination through a change in domestic law, all domestic debt, not only sovereign debt, would redenominate), but not by the domestic sovereign segmentation component.

To summarize, the baseline identification for Italy works as follows:

- The redenomination risk premium component is identified from the difference between the swap-adjusted corporate EUR bond yield and the corporate CDS rate.

\footnotetext{
${ }^{11}$ Several banks are known to have used ECB money to purchase their own bonds. This is less relevant for nonfinancials who do not have direct access to ECB borrowing.
} 
- The sovereign default risk premium component is identified from the swap-adjusted yield on the sovereign dollar-denominated bond.

- Given the redenomination risk premium component and the sovereign default risk premium component the swap-adjusted yield on the sovereign euro-denominated bond identifies the domestic sovereign segmentation component.

The details on exactly which securities are used are given in Table A.1. In terms of data sources we use mid-quote data from Bloomberg when available and otherwise data from Datastream. Bloomberg offers data from different sources. We use the CBBT or BGN data sources. Both of these sources are based on actual quotes from participating dealers (as opposed to a modelbased valuation). BGN is based on both executable and indicative quotes while CBBT uses executable quotes only. For each data series we pick between CBBT and BGN data by regressing the change in the series on five lags of the change in the series and picking the series for which this regression has the lower $\mathrm{R}^{2}$ indicating faster updating to news (absence of substantial positive coefficients on the lags) and less issues of measurement error (absence of substantial negative coefficients on the lags due to bid-ask bounce effects).

\section{Baseline implementation for Spain and Portugal}

For Spain and Portugal our baseline implementation shown in Table 2 Panel B is different from that used for Italy due to the different treatment of currency redenomination in CDS contracts. Since CDS rates for corporations in Spain and Portugal reflect both the default risk premium and the redenomination risk premium, as do euro-denominated bond yields, the difference between euro-denominated bond yields and CDS will not capture redenomination risk as it does for Italian firms. Instead, we exploit the fact that because CDS contracts for Spain and Portugal cover redenomination risk, if we compare the CDS rate for a corporation to the yield on a dollar denominated foreign-law bond of the same firm with a matched maturity, the difference will capture redenomination risk. Intuitively, the CDS works much like a eurodenominated bond in that it loads on both default and redenomination whereas the dollar bond only loads on default. We base our computations on the safest non-financial firm for which we can find data (in this case on CDS and dollar-denominated bonds) in order to minimize the non-redenomination component of the CDS-bond basis. For Spain we use the firm Telefonica and for Portugal the firm EDP (an energy company). The identification then works as follows:

- The redenomination risk premium component is identified from the difference between the corporate CDS rate and the corporate swap-adjusted USD yield. 
- The sovereign default risk premium component is identified from the swap-adjusted yield on the sovereign dollar-denominated bond.

- Given the redenomination risk premium component and the sovereign default risk premium component the swap-adjusted yield on the sovereign euro-denominated bond identifies the domestic sovereign segmentation component.

Finally, note that in order for the corporate CDS contracts to measure default and redenomination risk premia as we assume, the corporations on which the CDS contracts are written (Telefonica and EDP) must have euro-denominated local debt. Otherwise, the CDS rates will only reflect default risk premia. We have confirmed using Thomson One and Bloomberg data that both Telefonica and EDP (and the Spanish firm Endesa which we will use below) have outstanding local-law euro-denominated debt that is senior unsecured and thus could be delivered into the CDS contract in case of default or redenomination (the CDS contracts used are based on senior unsecured claims, meaning that in a credit event one can deliver anything of this or better seniority).

\section{Alternative implementation not relying on corporate CDS-bond basis}

Our baseline identification relies on comparing corporate bond yields and CDS rates to estimate the redenomination risk premium. We have picked the safest non-financial firms for which we have data in order to minimize the non-redenomination components of differences between bond yields and CDS, but this may not fully resolve the issue. If there are non-redenomination components in the CDS-bond basis, our results will be biased. As noted above, it is well documented that (swap-adjusted) bond yields were high relative to CDS rates in the US financial crisis, where there was no redenomination risk. If this is also true in Italy, our redenomination measure (which is based on Corporate EUR yield-EUR swap-Corporate CDS) will be upward biased, whereas for Spain and Portugal our redenomination series (which is based on Corporate CDS-(Corporate USD yield-USD swap)) will be downward biased. If ECB actions reduce market segmentation in general via increased arbitrage activity, it is likely that on ECB announcement dates the gap between corporate CDS rates and bond yields also shrinks. For Italy such a phenomenon will result in Corporate EUR yield-EUR swap-Corporate CDS falling and thus leading us to overestimate the extent to which ECB policies reduce redenomination risk. For Spain and Portugal, Corporate CDS-(Corporate USD yield-USD swap)) and Corporate CDS(Corporate GBP yield-GBP swap)) will increase from negative values towards zero and would lead us to underestimate the impact of ECB policies in reducing redenomination risk premia. Alternatively, the CDS-bond basis may change on ECB announcement days for reasons unrelated to ECB announcements and in ways not fully understood. For example, while Bai and Collin-Dufresne (2011) document clear patterns for average CDS-bond basis over time, there 
are large idiosyncratic components to the basis across companies and regressions explaining the basis have modest R2-values. For these reasons we also consider an alternative implementation which does not rely on identifying redenomination risk premia by comparing bond yields and CDS rates.

The alternative implementation is shown in Table 2 Panel C for Italy and Spain. For both countries, the alternative implementation provides an upper bound estimate of the level of the redenomination risk premium. Correspondingly, it will provide a lower bound estimate of the level of domestic sovereign bond segmentation. We use the yield on a euro-denominated local law bond (for Italy) or the CDS rate of a reasonably safe corporation (for Spain) to construct an upper bound estimate on redenomination risk and changes in redenomination risk on event dates by assuming that this yield/CDS rate reflects only redenomination risk. Since even the safest firms with yield/CDS data available have some default risk, this measure overstates the reduction of redenomination risk premia as a policy channel by implicitly assigning any reduction in the default risk premium for fairly safe corporations to a reduced redenomination risk premium.

For Italy we use the yield on the ENI bond used in our baseline implementation. For Spain we use the CDS rate for Endesa (the largest electric utility company in Spain, a firm with lower CDS rates than Telefonica) and also consider the yield for a euro-denominated local law bonds issued by Enagas (an energy company that owns and operates the Spanish national gas grid) or Abertis (an infrastructure conglomerate). Neither of these companies had enough data to be used for our baseline method but can be used in this alternative approach. For Portugal we do not have reliable data for any euro-denominated local-law non-financial bond and we cannot reliably use a non-financial CDS rate as an (upper-bound) measure of redenomination risk. While this made sense for Spain (where Endesa has a CDS rate of 2.5 percent or less throughout the sample), it makes less sense for Portugal were EDP's CDS reaches almost 10 percent in mid2012 and where EDP's foreign bonds have equally high yields suggesting that high CDS rates are mainly due to a default risk premium not a redenomination risk premium.

\section{Robustness check allowing for foreign segmentation in dollar bonds}

Our baseline estimation relies heavily on the use of dollar-denominated sovereign bonds. There are various concerns one may have with these, aside from the issue of whether they have the same default risk premium as local law euro-denominated bonds which we discussed above. Perhaps they are more illiquid than domestic bonds. Perhaps they have more measurement error. Perhaps the dollar-denominated bonds are taxed differently than other bonds, or are purchased by different investor clientele, which then affects their yields. If these effects lead to 
a level difference in dollar bond yields, then our inference will not be affected, since it is based on changes around event dates. If these effects are present as transient measurement error or illiquidity, then our Kalman filter will account for them. However, if these effects systematically change across ECB announcement dates, then our inference will be biased. As an example, if dollar-denominated bonds are less liquid than local bonds, they will carry an illiquidity discount. $^{12}$ If ECB actions systematically change the price that investors pay for liquidity, then the illiquidity discount may change across ECB announcement dates. To address these unresolved issues, we conduct a robustness check that allows for a separate segmentation component for dollar-denominated bonds. ${ }^{13}$

We assume that dollar-denominated bonds carry a foreign segmentation component and that this component is common to both sovereign and corporate bonds. While this would not make sense for euro-denominated bonds (due to ECB purchases focusing on sovereign bonds), it is more reasonable for dollar-denominated bond given that the segmentation component is intended to capture time-varying liquidity premia, tax or clientele effects and the effect of whether or not the bond is accepted as collateral by the ECB. We add additional information for corporations in order to estimate the foreign segmentation component. As before, we use dollar-denominated sovereign bonds to identify sovereign default, now adjusting our estimates of sovereign default risk premium for the fact that the dollar-denominated sovereign bonds are affected by the foreign segmentation component. The specific details again differ across countries as laid out in Table 2, Panel D.

For Italy, we add the yield on foreign law dollar-denominated bonds issued by ENI. The intuition for the identification works from the bottom to the top row: As in our baseline identification, we identify the corporate default component from the ENI CDS rate yield. Given the corporate default component we then use the dollar-denominated ENI bond yields to identify the foreign market segmentation component and use the euro-denominated ENI bond to identify redenomination risk. The sovereign dollar-denominated bond then identifies sovereign default risk premium leaving the sovereign euro-denominated bond to identify domestic sovereign segmentation.

\footnotetext{
${ }^{12}$ Foreign-currency bonds were not accepted as collateral by the ECB throughout much of our sample period. Collateral rules regarding dollar-denominated bonds changed on November 9, 2012, when the ECB resumed accepting foreign currency denominated collateral (this had also been done earlier in the crisis), subject to some further eligibility criteria (see https://www.ecb.europa.eu/paym/coll/html/questions2.en.html [retrieved on August 12, 2013]).

${ }^{13}$ Table A. 3 in the appendix reports an additional robustness check that probes the illiquidity issue. We use daily changes in the yield spread between German government bonds (Bunds) and German agency bonds (KfW) as a liquidity risk factor as in Schwarz (2010). We then estimate liquidity-risk related yield movements in the event windows as the liquidity betas multiplied by the change in the $\mathrm{KfW}$-Bund spread on the event days. We find that the liquidity-risk related yield changes are too small to explain much of the yield movements during the event windows. Moreover, the liquidity-risk related movements are quite similar for domestic and foreign-law bonds.
} 
For Spain we combine corporate information from Telefonica and Endesa. The intuition for the identification again works from the bottom to the top row of the table shown in Table 2, Panel D. We identify redenomination from the Endesa CDS by setting its corporate default premium component to zero as in the alternative implementation above. We then identify the corporate default premium for Telefonica from the Telefonica CDS. Given that, we can use the Telefonica dollar-denominated bond to identify foreign market segmentation. The sovereign dollar denominated bond then identifies the sovereign default premium leaving the sovereign eurodenominated bond to identify domestic sovereign segmentation.

For the data reasons discussed above, we cannot implement the robustness check allowing for foreign segmentation for Portugal.

\section{Non-synchronicity}

From a cursory look at the data (e.g., simple regressions) it is apparent that the securities we use as observables sometimes react to news in a delayed fashion. The foreign-currency denominated bonds, especially, tend to lag the other instruments in reaction to news. This could be due to stale prices of these bonds stemming from their low liquidity. We modify the state-space model to take this delayed reaction into account. The state vector is expanded to include $q$ lags of the latent components in addition to the $k$ unobservable components that we are interested in extracting:

$$
\left(\begin{array}{c}
x_{t} \\
x_{t-1} \\
\vdots \\
x_{t-q}
\end{array}\right)=\left(\begin{array}{c}
a \\
0_{k \times 1} \\
\vdots \\
0_{k \times 1}
\end{array}\right)+\left(\begin{array}{ccc}
F & 0_{k \times k(q-1)} & 0_{k \times k} \\
& I_{k q \times k q} & 0_{k q \times k}
\end{array}\right)\left(\begin{array}{c}
x_{t-1} \\
x_{t-2} \\
\vdots \\
x_{t-q-1}
\end{array}\right)+\left(\begin{array}{c}
u_{t} \\
0_{k \times 1} \\
\vdots \\
0_{k \times 1}
\end{array}\right)
$$

where $F$ is a diagonal matrix, as before. All this modification does is to expand the state vector with lags of $x_{t}$, but without any further change to the state-vector dynamics compared with eq. (2). The observation equation is now specified as

$$
y_{t}=\left(\begin{array}{c}
L_{1} \otimes H_{1} \\
L_{2} \otimes H_{2} \\
\vdots \\
L_{k} \otimes H_{k}
\end{array}\right)\left(\begin{array}{c}
x_{t} \\
x_{t-1} \\
\vdots \\
x_{t-q}
\end{array}\right)+w_{t}
$$

where the $L_{i}$ are row vectors, $\left(1, g_{i}, \operatorname{sgn}\left(g_{i}\right)\left|g_{i}\right|^{2}, \ldots, \operatorname{sgn}\left(g_{i}\right)\left|g_{i}\right|^{q}\right)$, that contain geometrically decaying weights, truncated after lag $q$, which are then rescaled so that the elements sum to a total weight of one. The $H_{i}$ vectors are the rows of $H$. This approach allows the observed yields and CDS rates to react to up to $q$ lags of the latent factors. For example, the first element of $y$ now no longer equals just $H_{1} x_{t}$, but instead only a weight $<1$ times $H_{1} x_{t}$ plus several lags of $H_{1} x_{t-}$ 
$j$, for $j=1,2, \ldots, q$, geometrically weighted. Thus, the degree of reaction delay is the same for each unobserved component, but it is allowed to differ across assets. This seems plausible. For example, when an asset does not react to news on a given day due to thin trading, it does not react to any news, whether it is news about, say, the default risk premium or the redenomination risk premium.

When we apply an event study analysis to the extracted latent components, having $q>0$ implies that we infer their reaction on day $t$ not only from asset price movements on day $t$, but also from movements on future days, up to day $t+q$, geometrically weighted. In other words, allowing for these lags allows us to effectively adjust the event window to a greater width depending on the degree to which an asset is prone to delayed reaction.

\section{Estimation}

We estimate the parameters of the state-space model $\{a, F, V, Q, g)$, where $g$ contains the stacked $g_{i}$ weighting parameters, with maximum likelihood using the Kalman filter algorithm. We choose the lag length $q$ to maximize the likelihood. Based on the estimated parameters, we then perform an additional Kalman smoothing step to obtain, at each point in time, the optimal estimates of the latent components based on the full sample of data from 2010 to 2012. Akin to a conventional event study with an extended event window, the Kalman smoother uses data from days before and after to average out noise in the estimation of the reaction of the latent components to the event. But unlike in a conventional event study, the effective window size and weights are chosen optimally depending on the statistical properties of the measurement error and the latent factors. For our main objective of analyzing the reaction of yield components ex-post, the smoothed estimates are the object of interest. To apply these methods for real-time monitoring of risks, one would omit the smoothing step.

\section{Channels for Policy Impact on Government Yields: Evidence}

We evaluate the effects of the ECB policies using an event-study approach. We construct 2-day changes, from the end of the day prior to the event to the end of the day after the event, (1) in observed asset prices around a set of event dates; and (2) in the extracted latent yield components around these event dates. Our event-study approach works only to the extent that we can be sure that market movements are largely due to ECB policy news. The dates we 
believe satisfy this criterion come from discussion of the programs in the previous section. As noted above, for the SMP, we use May 10, 2010 and August 7, 2011. ${ }^{14}$ For the OMT, we use July 26, 2012, August 2, 2012, and September 6, 2012. For the LTRO, we use December 1, 2011 and December 8, 2011.

There is a great deal of non-LTRO economic news over the LTRO period that complicates inference. In Italy, Mario Monti unveils a fiscal plan of austerity on December 5, 2011 that appears to significantly impact asset prices. In Spain, Mariano Rajoy introduces a fiscal plan on December 19, 2011 that appears significant. There is further news regarding these plans and whether or not they will be passed that arrives over this period that likely have important effects on asset prices.

The measured changes around the event dates should be thought of as asset price reactions to changes in the probability of a given ECB program, rather than measures of the full magnitude of the effect of the ECB program. To the extent that we focus on only a few dates for each event which we are sure are program-relevant dates, it is likely that our measured magnitudes severely understate the impact of the program. The issue is likely most important for the LTRO where it is clear that news arrives continuously over a long interval, and we focus only on two dates. It is also important to keep in mind that the measured price changes reflect financial markets' initial assessment of these programs, which is not necessarily equal to the eventual impact of the program. ECB announcements about the SMP and OMT did not contain information about the likely magnitude, nor the distribution across countries or maturities, of intended purchases. Furthermore, banks' use of LTRO funds was also uncertain. Given this, our event study evidence should be interpreted as being driven by the market's perception about the likely outcome of the programs.

\section{A. Effects on Bond Yields}

We start by examining the impact of the ECB policies on government bond yields. We consider government bond yields from 6 months to 10 years, obtained from Bloomberg along with overall country level government bond index yields from Barclays obtained from Datastream. For some of the dates, we do not have data for some yield series (indicated as "ND" (no data) in the tables below).

Table 3 reports 2-day changes in government bond yields around the SMP, OMT, and LTRO event dates. Bond yields fall dramatically in all of the countries for the SMP and OMT. The

\footnotetext{
${ }^{14}$ The August 7, 2011 announcement falls on a weekend day. For that event, we use the change from the end of Friday to the end of Tuesday.
} 
largest reductions are at the 2- and 5-year maturities with both Italian and Spanish yields falling around 200 bps due to both the SMP and the OMT. The reductions are generally significant at the $5 \%$ level (indicated by boldface). ${ }^{15}$ For the LTROs, bond yields fall in Italy, Spain and Ireland, with the largest effect of around 50 bps at the 2-year maturity seen for Spain, whereas yields do not fall in Portugal and Greece. Given the volatility in Portuguese and Greek bond yields over this period, it is possible that other news may have outweighed the LTRO effect in Portugal and Greece. The yield changes for the overall LTRO effect are not significantly different from zero for any of the GIIPS countries. However, as we will see when we examine the latent components of bond yields, the LTROs had significant effects on the sovereign segmentation component of Spanish yields.

\section{B. Channels for Effects on Bond Yields}

We first examine the signaling and duration-risk channel in Table 4. The table presents the 2day changes in the Euro swap rate (EONIA OIS) across the event dates. It is evident that the general change in interest rates across the event dates is small, especially compared to the changes in GIIPS sovereign bond yields. That is, the signaling and duration risk channels played a small role in the impact of ECB policies.

We next turn to more detailed evidence on the relative roles of the default risk premium, the redenomination risk premium, and the segmentation channel in the impact of ECB policies on sovereign bond yields. In this analysis, bond yields are expressed as a spread over the swap rate to strip out the signaling and duration risk effects. For data availability reasons we focus on Italy, Spain and Portugal.

Italy

Figure 3 Panel A shows swap-adjusted sovereign bond yields on domestic-law EUR bonds and foreign-law USD bonds for Italy for a pair of bonds maturing in 2015, as well as the difference between the two series which captures redenomination and domestic sovereign segmentation.

\footnotetext{
${ }^{15}$ To assess statistical significance of the yield change for a particular policy announcement (for a given country and maturity) we regress (for each country) daily yield changes from 2010 to 2012 on policy announcement dummy variables. For each policy announcement (e.g. the first SMP announcement) the corresponding dummy variable is set to one on the event date and the following day and we test for the significance of this dummy variable. To assess statistical significance of yield change totals across several announcement dates for a given policy (e.g. the total impact of SMP for a given country, across the two announcements) we estimate the same regressions but use dummy variables set to one on days on which an announcement is made and on the first day after an announcement is made.
} 
These series are part of the input that we use to estimate the state-space model to extract the latent components of bond yields. Table A.1 in the Appendix lists the specific securities that we use. The vertical lines in Figure 3 mark event dates.

The figure provides a preliminary indication that the default risk premium plays the dominant role in explaining the movements in bond yields in Italy. The swap-adjusted yield on the USD bond is of similar magnitude as the swap-adjusted EUR bond yield, indicating the importance of the default risk premium. There is, however, also substantial movement in the redenomination plus domestic sovereign segmentation component of the EUR bond yield, underscoring the importance of carefully identifying the various components and their relative changes around event dates. For that purpose Figure 3 Panel B shows the series for ENI EUR bonds and ENI CDS used to identify redenomination risk in our baseline approach. The swap-adjusted ENI EUR yield rises substantially before the SMP dates, before the first LTRO date and before the first OMT date. However, so does the ENI CDS rate. Therefore, the difference between the two ENI series, which captures redenomination, is generally small. This suggests that redenomination risk is unlikely to have played a major role for yields in Italy. ${ }^{16}$ Recall that the work of Bai and CollinDufresne (2011) finds that swap-adjusted yields tend to exceed CDS rates during crisis times even absent redenomination risk, suggesting that this conclusion is unlikely to be driven by CDS bond-basis biases.

We next turn to the Kalman filter analysis which accounts for lags in the reaction of asset prices to news. Table 5 presents our estimates for how the observable variables load on contemporaneous and lagged values of the latent factors in our baseline specification (as outlined in Panel B of Table 2). For the Italian securities, ML estimation suggests truncation after lag 2; for Spain and Portugal, ML estimation suggests truncation after lag 3 and lag 2, respectively. From lag 1 onwards the weights decay geometrically, and, together with the "lag 0 " coefficient, they always sum to one. Table 5 shows the weights. The delayed reaction issue is particularly important for foreign-currency bonds. The weight on the contemporaneous latent factor realization at "lag 0 " is less than 0.50 in some cases. CDS and domestic bond yields react with less delay.

We repeat the event study analysis with the latent components of bond yields that we extract using the Kalman filter. The changes in the extracted latent components over the two-day

\footnotetext{
${ }^{16}$ This result contrasts with that of observers focusing on the (negative) CDS-bond basis of Italian sovereign bonds which was higher than that for ENI bonds just before the LTROs and which some have suggested indicated substantial redenomination risk for Italy at that time (see in particular Di Cesare, Grande, Manna and Taboga (2012)).
} 
event windows are presented in Table 6. ${ }^{17}$ Columns labeled with (i) show the estimates from our baseline specification as outlined in Panel B of Table 2. Columns labeled with (ii) present the estimates from the specification in Panel $C$ of Table 2 that does not rely on the CDS bond basis. These estimates provide an upper bound estimate of the role of redenomination risk. Columns labeled with (iii) show the results corresponding to Panel D of Table 2 where we allow for the possibility that foreign currency bond yields contain a foreign market segmentation component reflecting their illiquidity and specific investor clientele.

The first Panel in Table 6 presents the results for Italy. The estimates from the three different specifications are broadly similar. The effects of SMP and OMT on the one hand and the LTROs on the other are markedly different.

We find a strong and significant reduction of the default risk premium component by 31 to 117 basis points for each of the SMP and the OMT. The domestic market segmentation component is also strongly affected by SMP and OMT. It declines by between 79 and 133 basis points for each of these policies. Almost all of these changes are significant at the 5 percent level.

In contrast, the redenomination component for Italy remains virtually unchanged around event dates. Method (ii) suggests some role for reduced redenomination risk but remember that method (ii) was designed to provide an upper bound estimate on the role of redenomination by using the swap-adjusted EUR yield for a fairly safe non-financial firm (ENI) to measure redenomination risk. Some part of the -24 bps reduction for the SMP and -48 bps reduction for the OMT is thus likely to be due to a reduced default risk premium not a reduced redenomination risk premium, as suggested by method (i) and (iii) which exploit information on ENI default risk from ENI CDS.

The LTROs have comparatively small effects in the case of Italy, with the only significant effect a 34 to 40 bps reduction in the default component.

Figure 3, Panel C plots the entire time series of the extracted default risk premium, redenomination risk premium, and domestic market segmentation components in our baseline specification corresponding to the our baseline identification in Table 2 Panel $B$ and the results shown in Table 6 column (i).

\section{Spain}

\footnotetext{
${ }^{17}$ The total effect summed across all components is not exactly equal to the bond yield effects shown in Table 3 , for several reasons: First, Table 3 looked at constant-maturity yields, while the state-space model is applied to specific bonds with a fixed maturity date (see Table A1 in the appendix for a list of the specific instruments used). Second, the Kalman filter allows for measurement error and delayed reactions of yields.
} 
Figure 4 Panel A plots the swap-adjusted EUR and USD yields for a pair of Spanish government bonds maturing in 2013. As with our analysis of Italy, the evidence suggests that the dominant factor driving yields is the default risk premium since the dollar-denominated bonds (which are not subject to redenomination risk and less affected by ECB-induced changes in market segmentation) have yields that are quite similar to those for the euro-denominated bonds. There is, however, also substantial movement in the redenomination plus domestic sovereign segmentation component of the EUR bond yield. This component drops substantially around the LTRO dates. To separate redenomination and segmentation, Figure 4 Panel B plots the Telefonica series used in our baseline approach. The difference between the Telefonica CDS and the swap-adjusted Telefonica USD yield, which captures redenomination risk, does not move sharply around the LTRO dates. Together, Panel A and B of this figure thus suggests that the LTROs substantially reduced domestic sovereign segmentation for Spain. To more carefully assess the changes in the various components around event dates, Table 6 shows (in the middle panel) the Kalman filtering results for Spain.

The results in Table 6 for Spain paint a similar picture for the SMP and OMT to that found for Italy with regards to the policies' impact on the default risk premium and domestic sovereign segmentation. These components fall by similar magnitudes as in Italy. The default risk premium falls by between 44 and 96 bps for each of the SMP and OMT and domestic sovereign segmentation by between 73 and 87 bps for each of the SMP and OMT. In addition, however, Spanish bonds experienced a substantial drop in the redenomination risk premium component around the SMP and OMT announcements, with reductions between 20 and 56 basis points.

The result that the redenomination risk premium was reduced by the SMP and OMT for Spain is robust across methods, i.e. to whether we identify redenomination risk from the difference between the Telefonia CDS and swap-adjusted Telefonica USD yields (method (i)) or from Endesa CDS (method (ii) and (iii)). The series for Endesa is shown in Figure 4 Panel D. The reductions in the Endesa CDS on the first SMP date and the first and third OMT dates (the dates that drive the overall results as seen in Table 6) are visible in the graph.

Figure 4, Panel C plots the entire time series of the extracted default risk premium, redenomination risk premium, and domestic market segmentation components in our baseline specification. In interpreting this figure, it is useful to keep in mind that the extracted series do not necessarily represent an accurate picture of the level of a component. In our baseline specification for Spain, the redenomination component is identified, roughly speaking, as the difference between the Telefonica swap-adjusted USD yield and Telefonica's CDS rate (see Table 2 Panel B). If the USD bond yield is elevated to compensate for the bond's illiquidity, the extracted redenomination risk component is biased downward and can be negative, as in the figure. However, if the illiquidity component in the USD yield does not change much on the ECB 
policy announcement date, our event study results in Table 6 will still provide an accurate measure of the change in the redenomination component around the event date. Moreover, we study the policies with three different specifications in which the bias goes in different directions, and the results are robust across methods.

As a further robustness check on the role of redenomination risk for Spain, we look for domestic non-financial euro-denominated corporate bonds. These are rare, but in Figure 4 Panel D we include two available series for Enagas (a gas distribution utility) and Abertis (an infrastructure firm), again shown as yields in excess of swap rates. There appears to be some movement in these yields around the OMT dates, but not much change around the first SMP date. It is possible that our estimates in Table 6 overstate the impact of redenomination risk around the first SMP date. However, even based on the Table 6 estimates, the reduction in the redenomination risk premium is smaller than the reduction in the default risk premium and the effect on domestic market segmentation. Thus, our overall conclusion for Spain with regard to the SMP and OMT is similar to that for Italy: The market perceived these policies to mainly affect domestic government bond yields via a reduced default risk premia and via effects on domestic sovereign segmentation.

The LTROs have a different effect than the SMP and OMT. As in Italy, there is not much effect of the LTROs on the default risk premium and redenomination risk premium components, but unlike in Italy, the domestic market segmentation component falls strongly with magnitudes of 69 to 83 basis points consistent with our earlier discussion of this based in Panel A and B of Figure 4. The fact that we find a substantial effect of the LTROS for Spain via the domestic market segmentation components is consistent with the data in Table 1 Panel B. As a percentage of the outstanding debt, the resident banks' purchases of domestic sovereign bonds over the period from 2011:Q3 (pre-LTRO) to 2012:Q2 (after the second allotment of LTRO money was dispersed) were much larger in Spain (about 10 percent of the bonds outstanding for Spain and about 5 percent for Italy and 2 percent for Portugal).

\section{Portugal}

Figure 5 Panel A plots the swap-adjusted EUR and USD yields for a pair of Portuguese government bonds maturing in 2015. As with our analysis of Italy and Spain, the fact that the USD-denominated bonds have yields close to those of the domestic bonds suggests that the dominant factor driving yields is the default risk premium.

The results of the Kalman filter analysis is in the bottom panel of Table 6. For the SMP and $\mathrm{OMT}$, the results are similar to those from Spain with the largest channels being reductions in 
the default risk premium and lowered bond yields via reduced domestic sovereign segmentation. Reduced redenomination risk plays a smaller role. The effects of the LTROs in Portugal are insignificant for all yield components.

Overall we conclude from our analysis that: (a) Default risk premium and domestic sovereign segmentation effects were the dominant channels through which the SMP and the OMT affected sovereign bond yields of Italy, Spain, and Portugal; (b) Redenomination risk may have been present at times and it may have been a third policy channel for the SMP and OMT in the case of Spain and Portugal, but not for Italy. (c) The effects of the LTROs are generally small except for Spain for which they appear to have reduced sovereign bond yields via the domestic sovereign segmentation channel. On average across Italy, Spain and Portugal, considering both the SMP and OMT and using Table 6(i), reduced default risk accounts for $37 \%$ of the reduction in bond yields, reduced redenomination risk for $13 \%$, and reduced market segmentation for $50 \%$.The fact that we do find some role for redenomination risk as a policy channel in Spain and Portugal is consistent with the ECB's frequently stated concern about redenomination risk. However, it is important to emphasize that while the ECB's concerns about redenomination risk appear to have been most intense just prior to the OMT, motivated by perceptions of high redenomination risk for Spain, our estimates suggest that even for Spain, the OMT worked mainly via an impact on the default risk premium and domestic sovereign segmentation with only a smaller role for reductions in redenomination risk.

The role for the domestic sovereign segmentation channel is potentially consistent with the ECB stating "dysfunctional" markets as a central motivation for the SMP, although the fact that the market segmentation component turns negative in Spain and Italy could indicate that the ECB policies lead to a "negative" segmentation effect where domestic yields were temporarily depressed due to "excess demand" for domestic bonds (from the ECB or domestic banks).

\section{Greece}

Our decomposition analysis up to this point excluded Greece. Our identification schemes cannot be applied to Greece because we lack suitable yield and CDS data. To identify the redenomination risk premium component, we require either a company that has foreigncurrency international debt outstanding along with either CDS or euro-denominated domestic bonds (method i), or a safe corporation with CDS or euro-denominated domestic bonds. method ii). In Greece, there is no suitable candidate company that would satisfy these requirements. 
For these reasons, we pursue a more limited analysis for Greece. Figure 6 plots the yields of domestic EUR-denominated Greek sovereign bonds and the yield of USD-denominated foreignlaw sovereign bonds, both maturing in 2013 and expressed relative to EUR and USD swap rates, respectively. The difference between the two yield series, domestic minus foreign yield, represents a combination of the redenomination risk component and domestic sovereign segmentation effects. It is shown in the figure as the blue line. The vertical lines represent the two SMP announcement events. We focus on the period up to August 2011 because data become erratic or unavailable after that.

As Figure 6 shows, the swap-adjusted domestic bond yield fell dramatically, by 897 bps, in the 2-day window around the first SMP announcement day. In comparison, there is a small rise of 42 bps on the second SMP date, consistent with the focus on the second wave of the SMP on Italy and Spain. In the 2-day window around the first SMP date, the swap-adjusted USD yields fell by 533 bps, far less than the domestic yield, leading the redenomination plus domestic sovereign segmentation component to fall by 364 bps. Therefore, while the default risk premium channel (captured by the USD bond) was the most substantial, an important additional policy channel for the SMP was its impact on redenomination or domestic sovereign segmentation. The redenomination plus domestic sovereign segmentation component becomes substantially negative after the first SMP date. Since redenomination risk cannot be negative this suggests that a substantial channel through which the SMP impacted Greek bond yields was the domestic sovereign segmentation channel. The actual and expected ECB purchases thus reduced the yields bonds to be purchased (domestic) relative to those that the ECB would not purchase (foreign). This evidence of negative domestic sovereign market segmentation effects is consistent with the evidence in Trebesch and Zettelmeyer (2014) that drops in yields were concentrated among those particular domestic bonds that the ECB actually purchased after the announcement.

\section{Macroeconomic Impact}

To assess the broader macroeconomic impact of the ECB policies, beyond their effects on sovereign bond yields, we now turn to asset price reactions of and changes in the aggregate market values of stocks and corporate bonds. 
Table 7 Panel A reports changes in country level stock indices. The stock returns are calculated using the Datastream indices ${ }^{18}$. For the SMP and OMT, stock returns rise across the board. The effect of the OMT is the largest, with the overall EMU index increasing by over $13 \%$. For the LTROs, the stock return evidence is mixed with some countries experiencing positive returns and others experiencing negative returns, but none of the LTRO effects are statistically significant.

In Panel $B$ and $C$ we break out the stock results into financial sector stocks and non-financial stocks. Effects are larger for financial sector stocks but even non-financial stocks increase around $12 \%$ on the OMT event dates. We have seen in Table 3 that the ECB policies increased government bond prices. Since the financial sector holds a large amount of government bonds, it is likely that the financial sector stock returns are influenced by the direct gain on the value of bond holdings (e.g. Acharya and Steffen, 2015). In Table 8 we assess how much of the financial sector stock returns on the event dates can be explained by the gain on GIIPS sovereign bond holdings. The table is based on banks that both provided data to the EBA's 2011 stress test and were publicly traded on the particular event date with data available in Compustat Global Security Daily. We compare actual (value-weighted) stock returns for these banks to returns implied by the change in the market value of their sovereign bond holdings. The number of banks varies between 31 and 35 across event dates, but since the banks in the EBA stress test are the largest ones in each country their stock returns are likely the key drivers of the country level financial sector stock returns (which are value-weighted). We calculate implied stock returns based on reported holdings of each of the GIIPS countries' sovereign bonds by maturity bucket, along with our documented yield changes by maturity from Table 3.

The table suggests that for many countries, only a small fraction of the large financial sector returns on the first SMP event date and the first and third OMT event dates can be explain by the increase in market value of GIIPS sovereign bonds held by financial institutions. The exceptions are Portugal, Greece, Germany and Belgium. In the sample of banks and event dates, the implied return has little explanatory power for actual returns (whether controlling for market beta or not). Instead, returns are much better explained by the bank's market beta on the Eurostoxx index (SXXT, a fairly broad index with about 300 firms included) multiplied by the realized 2-day return on this index around the particular event date. In a regression of 2-day stock returns using all seven announcement dates and all 35 banks with sufficient data, the bank-level stock return implied by GIIPS sovereign bond holding has a small (near zero) and insignificant coefficient whereas beta (estimated recursively using the past 120 days of returns) multiplied by the 2-day market return around the event has coefficient close to 1 (significant at

\footnotetext{
${ }^{18}$ We use Datastream indices rather than $\mathrm{MSCl}$ indices because Datastream indices use all stocks whereas $\mathrm{MSCl}$ indices are based only on free float.
} 
the $1 \%$ level). We do not include the regression in a table for brevity. This finding suggests that financial sector stock returns cannot be explained primarily by sovereign bond holdings but instead are likely to be driven by a more general impact of policies on the economies. This is consistent with substantial policy effects on non-financial stocks in Table 7 Panel C.

Table 9 presents changes in corporate bond yields. We use the Barclays indices for corporate bonds, with data available for Italy and Spain, and Portugal for part of the period. The average durations of the corporate bond indices are around 4 years. The OMT appears to have had the largest effect on corporate yields, with larger effects for Spain than Italy, but with effects much smaller than those documented for sovereign bonds in Table 3. The corporate bond yield indices are a based on a mix of domestic law euro-denominated bonds and foreign law eurodenominated bonds (Eurobonds). They are thus difficult to interpret in terms of channels (default vs. redenomination) because foreign law euro-denominated bonds under some circumstances likely could be redenominated even if under foreign-law (if the euro ceased to exist as a currency, see Nordvig and Firoozye, 2012). The corporate bond indices are nonetheless useful for understanding whether corporations benefitted from ECB policies and thus for assessing the broader macroeconomic impact of these policies. ${ }^{19}$

\section{B. Quantifying the Policy Impact}

We next do some simple calculations to assess potential welfare effects of the SMP and OMT. Table 10 reports the total change in stock market value and value of government and corporate bonds ( $€$ Billions), based on 2-day changes in asset prices, focusing on the SMP and OMT, which are the policies with strong effects on valuations. From the table, we compute that the increase in the market value of GIIPS bonds is $€ 280$ billion (corporate bonds account for only around $€ 5$ billion of this as indicated by the last column which is based on sub-indices for corporate bonds, available for Italy, Spain and Portugal). The increase in the stock market value for GIIPS countries is $€ 161$ billion, while it is $€ 769$ billion for the EMU as a whole.

One metric for the benefit of these policies is the increase in asset values across the Euro area. One can view the change in the stock market value as a proxy for the change in present value of cash flows generated by the private sector (net of taxes), and the change in bond values as a proxy for the change in the present value of cash flows to bond holders. The total market value increase in GIIPS debt and EMU stock market is $€ 1,049$ billion (=€280 billion $+€ 769$ billion). As

\footnotetext{
${ }^{19}$ We have also examined exchange rate reactions on the event dates. Using the trade-weighted index of the Euro exchange rate from the ECB (series EXR.D.E5.EUR.ENO0.A) we find no significant changes in the Euro exchange rate around out SMP, OMT or LTRO event dates. This suggests that changes in euro-zone competitiveness via changes in the Euro is unlikely to have been a major channel through which beneficial macroeconomic effects have worked for these policies.
} 
noted above, there is likely some double counting in this computation since the increase in bond values directly increase financial-sector stock market values. A conservative approach to address this is to assume that $100 \%$ of the increase in bond values is reflected in the stock market increase. In this case, the market value increase due to the policy is $€ 769$ billion. Alternatively we can use the Bruegel data from Table 1 Panel B to assess what fraction, $f$, of GIIPS sovereign debt is owned by GIIPS and core country banks and estimate the overall market value increase as $(1-f)^{*} € 280$ billion $+€ 769$ billion. Using resident bank holdings from the Bruegel data along with an estimate of the ratio of GIIPS plus core bank holdings to resident bank holdings from the data on the 2011 EBA stress test discussed above, we estimate that $f$ varies between $25.7 \%$ and $37.9 \%$ across the GIIPS countries (column (8)-(9) of Table 1 Panel B). If we set $f$ to $1 / 3$ (for both sovereign bonds and corporate bonds), we find a market value increase due to the SMP and OMT of $€ 955$ billion. This benefit is likely an underestimate because we implicitly assume that all banks are publicly traded and, more importantly, because it neglects any market value changes for non-publicly traded firms, along with wage gains via reduced economic contraction.

The cost of the policy depends on the underlying problem addressed by the policies. If the underlying problem is one of multiple equilibria created by rollover risk, or if the problem is high bond yields caused by segmentation and illiquidity problems, then the ECB policies may cost zero, and could in theory turn a profit for the ECB. In the pure multiple equilibrium case, a policy announcement such as OMT rules out the bad equilibrium at zero cost. In the case where bond yields are high because of illiquidity/segmentation frictions, the SMP is profitable as the ECB earns an abnormal return on its purchases of bonds.

If the underlying problem is one of pure solvency, then these policies may have positive costs to the ECB (or to taxpayers from core countries). An upper bound on this cost is the increase in the market value of GIIPS government debt of around $€ 275$ billion. Suppose that the SMP and OMT are viewed as signals that in the event of a sovereign (near-) default, there will be fiscal transfers from core countries to the affected countries. Then, the SMP and OMT lower bond yields because they reduce the default risk premium of bond-holders. In this case, the expected fiscal transfer is equal to the increase in the value of GIIPS government debt. ${ }^{20}$

The $€ 275$ billion number is thus an upper-bound cost to core-country taxpayers. To the extent that the holders of the GIIPS bonds are investors from the core countries, some of the increase in value of the GIIPS bonds cycles back to the core-countries. In other words, part of this number could reflect risk that is shifted from core bond investors (most likely financial institutions, to which core taxpayers are indirectly exposed) to core taxpayers.

\footnotetext{
${ }^{20}$ In order to not double-count the costs of the programs to core tax payers we do not consider the effects of the programs on the market values of core-country sovereign or corporate bonds.
} 
A further caveat is that this calculation does not capture the potential costs to core taxpayers from future debt issues of GIIPS sovereigns that raise the amount of outstanding debt (rather than rolling over existing debt). If investors believe that fiscal transfers will be forthcoming in the event of a sovereign debt crisis, GIIPS countries could issue debt at higher prices. This fiscaltransfer-induced increase in the market value of future net debt issues is not captured in our calculation. One can view the conditionality in the OMT program as an attempt to prevent such fiscal transfers induced by future debt issues. A related issue in terms of potential costs of the programs is whether the ECB has "lost reputation" in keeping inflation low. Figure 7 graphs a measure of 10-expected inflation for the euro area based on inflation swap contracts. While there are increases in expected inflation around some of the announcement dates expected 10year inflation remains around 2\% in 2013 suggesting that any such reputation loss has been small. Low, not high, inflation has been the concern for the ECB in the years since the onset of the debt crisis.

As noted above, the right way to look at these numbers is on a relative basis. The ratio of benefit to cost is at least $€ 955 / € 275$, indicating that the policies have been potent in improving the expected macroeconomic situation.

\section{Conclusion}

We began with the observation that European government bond yields have been high at various times from 2010 to 2012. We then documented the basic impact of three ECB policies on sovereign bond yields in GIIPS countries finding that the SMP and OMT were much more effective at reducing sovereign yields than the LTROs. The main contribution of the paper was then to provide a new framework for how to decompose the policy-induced yield changes in order to determine how policies succeeded in lowering yields. The default risk premium and sovereign bond segmentation effects appear to be the dominant channels through which the SMP and the OMT affected sovereign bond yields. A redenomination risk premium may have been present at times and it may have been a third policy channel for the SMP and OMT in the case of Spain and Portugal, but not for Italy. As for the LTROs, the effects of the LTROs on sovereign yields are generally small except for Spain for which they appear to have reduced sovereign bond yields via the sovereign segmentation channel. Importantly, we find that the ECB's policies have had beneficial macroeconomic spillovers. That is, ECB actions have not merely engineered transfers from core countries to GIIPS countries, as suggested by some observers. For the SMP and OMT we document these effects by measuring stock returns around ECB announcement dates, for both GIIPS and EMU countries. 
Beyond the specific ECB policy actions we have studied, the methodology of the paper can be used to monitor and diagnose Eurozone risks in real-time. That is, our methodology offers a decomposition of yield movements into default risk premium, segmentation and redenomination risk premium components. Understanding these channels may be useful to policy-makers in responding to Eurozone shocks. For example, suppose yields on European sovereigns suddenly spiked, and our methodology suggests that the spike is largely due to a rise in redenomination risk. In this case, actions such as the OMT may more directly and more effectively stabilize the economy than, for example, a liquidity injection into banks.

\section{References}

Acharya V., Steffen S. (2015) The "greatest" carry trade ever? Understanding eurozone bank risks, Journal of Financial Economics 115, 215-236.

Aguiar M., Amador M. (2014). Sovereign Debt, in: Handbook of International Economics Vol. 4, Elsevier, Amsterdam.

Andrade P., Cahn C., Fraisse H., and Mesonnier J.-S. (2015) Can the provision of long-term liquidity help to avoid a credit crunch? Evidence from the Eurosystem's LTRO, Banque de France. Working Paper.

Bai J., Collin-Dufresne P. (2011) The determinants of the CDS-bond basis during the financial crisis of 2007-2009. Columbia University. Working Paper.

Carpinelli L., Crosignani M. (2015) The effect of central bank liquidity injections on bank credit supply, New York University. Working Paper.

Cole H., Kehoe T. (2000) Self-fulfilling debt crises, Review of Economic Studies 67, 91-116.

Corradin S., Rodriguez-Moreno M. (2013) Limits to arbitrage: empirical evidence from euro area sovereign bond markets, European Central Bank. Working Paper.

Credit Suisse (2010) Sovereign CDS Primer.

Crosignani M., Faria-e-Castro M., Fonseca L. (2015) Central bank interventions, demand for collateral, and sovereign borrowing costs, New York University. Working Paper.

De Pooter M., Martin R. F., Pruitt, S. (2012) The effects of official bond market intervention in Europe, Federal Reserve Board. Working Paper.

Di Cesare A., Grande G., Manna M., Marco, T. (2012) Recent estimates of sovereign risk premia for Euro-area countries, Banca d'Italia. Working Paper. 
Duffie D., Singleton K. J. (1999) Modeling term structures of defaultable bonds. Review of Financial studies 12, 687-720.

Duffie D. (2010) Presidential address: asset price dynamics with slow-moving capital, Journal of Finance 65, 1237-1267.

Eser F., Schwaab B. (2013) Assessing asset purchases within the ECB's securities market programme, European Central Bank. Working Paper.

Falagiarda M., Reitz S. (2015) Announcements of ECB unconventional programs: Implications for the sovereign risk of Italy, Journal of International Money and Finance 53, 275-295.

Feldhütter P., Lando D. (2008) Decomposing swap spreads, Journal of Financial Economics 88, 375-405.

Garcia-Posada M., Marchetti M. (2016) The bank lending channel of unconventional monetary policy: The impact of the VLTROs on credit supply in Spain, Economic Modelling 58, 427-441.

Garzarelli F. (2012) Global markets daily: Can the EMU sovereign bond-CDS 'basis' normalize?, Goldman Sachs. Research Note.

Greenwood R., Vayanos D. (2010) Price pressure in the government bond market, American Economic Review 100, 585-90.

Gromb D., Vayanos D. (2002) Equilibrium and welfare in markets with financially constrained arbitrageurs, Journal of Financial Economics 66, 361-407.

Ivashina V., Scharfstein D. S., Stein J. C. (2015) Dollar funding and the lending behavior of global banks, Quarterly Journal of Economics 130, 1241-1281.

Krishnamurthy A., Vissing-Jorgensen A. (2011) The effects of quantitative easing on interest rates, Brookings Papers on Economic Activity, Fall 2011, 215-287.

Krugman P. (1988) Financing vs. forgiving a debt overhang, Journal of Development Economics 29, 253-268.

Lamont O., Thaler, R. (2003) Can the market add and subtract? Mispricing in tech stock carveouts, Journal of Political Economy 111, 227-68

Mitchell M., Pulvino T., Stafford E. (2002) Limited arbitrage in equity markets, Journal of Finance 57, 551-84

Myers S. (1977). The Determinants of corporate borrowing, Journal of Financial Economics 5, 147-175. 
Nordvig J., Firoozye N. (2012) Planning for an orderly break-up of the European Monetary Union, submission to the Wolfson Economic Prize.

Reinhart C., Rogoff K. (2011) The forgotten history of domestic debt, Economic Journal 121, 319-350.

Szczerbowicz U. (2015) The ECB unconventional monetary policies: have they lowered market borrowing costs for banks and governments?, International Journal of Central Banking 11, 91127.

Schwarz K. (2010) Mind the gap: Disentangling credit and liquidity in risk spreads, Wharton School. Working paper,.

Trebesch C., Zettelmeyer J. (2014) ECB interventions in distressed sovereign debt markets: The case of Greek bonds, University of Munich. Working Paper.

Zettelmeyer J., Trebesch C., Gulati M. (2013) The Greek debt restructuring: An autopsy, Economic Policy 28, 513-563. 
Figure 1. 2-Year Government Bond Yields, 2010 to 2012
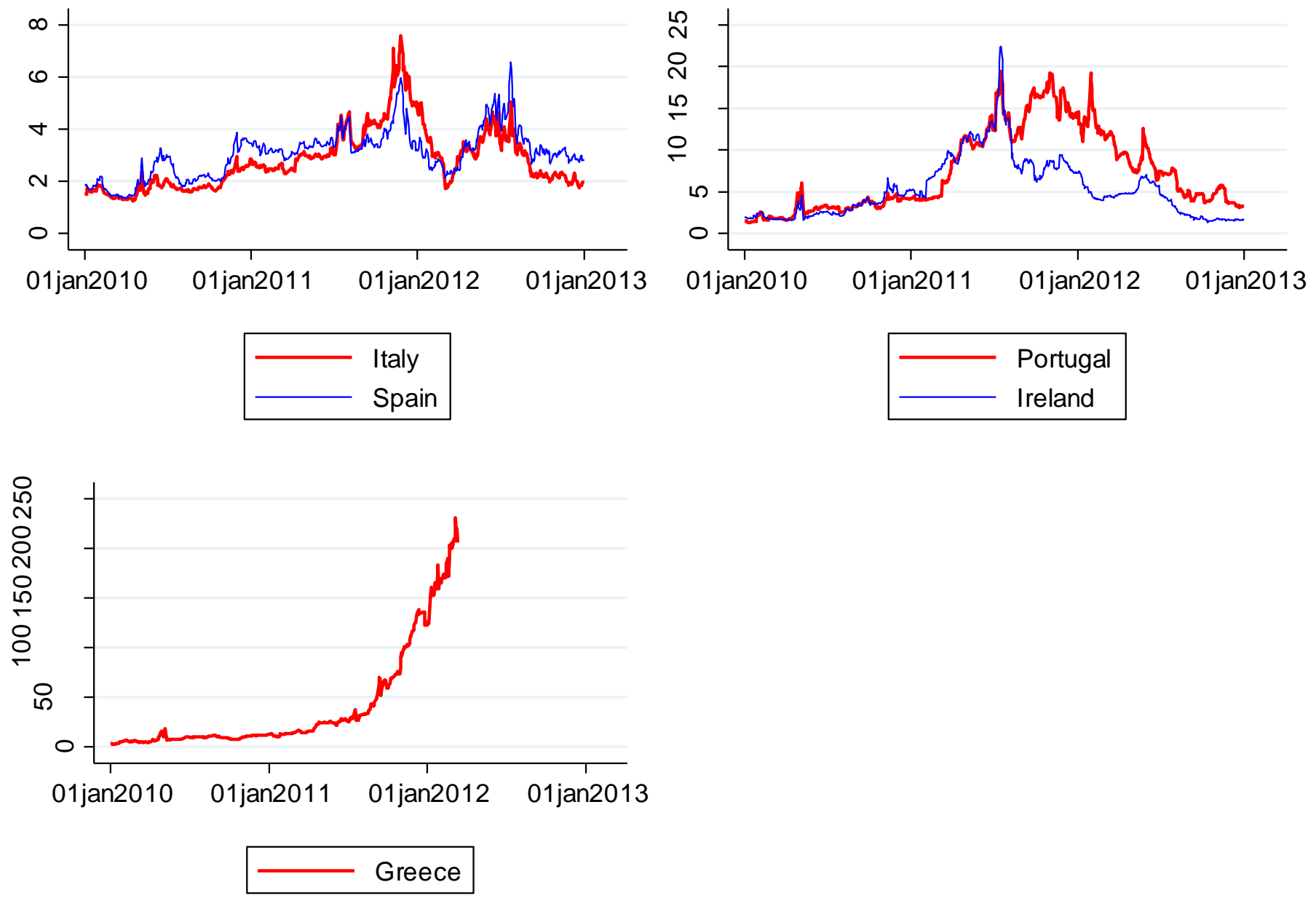

Source: Bloomberg 
Figure 2. ECB bond holdings under the Securities Markets Programme (SMP)

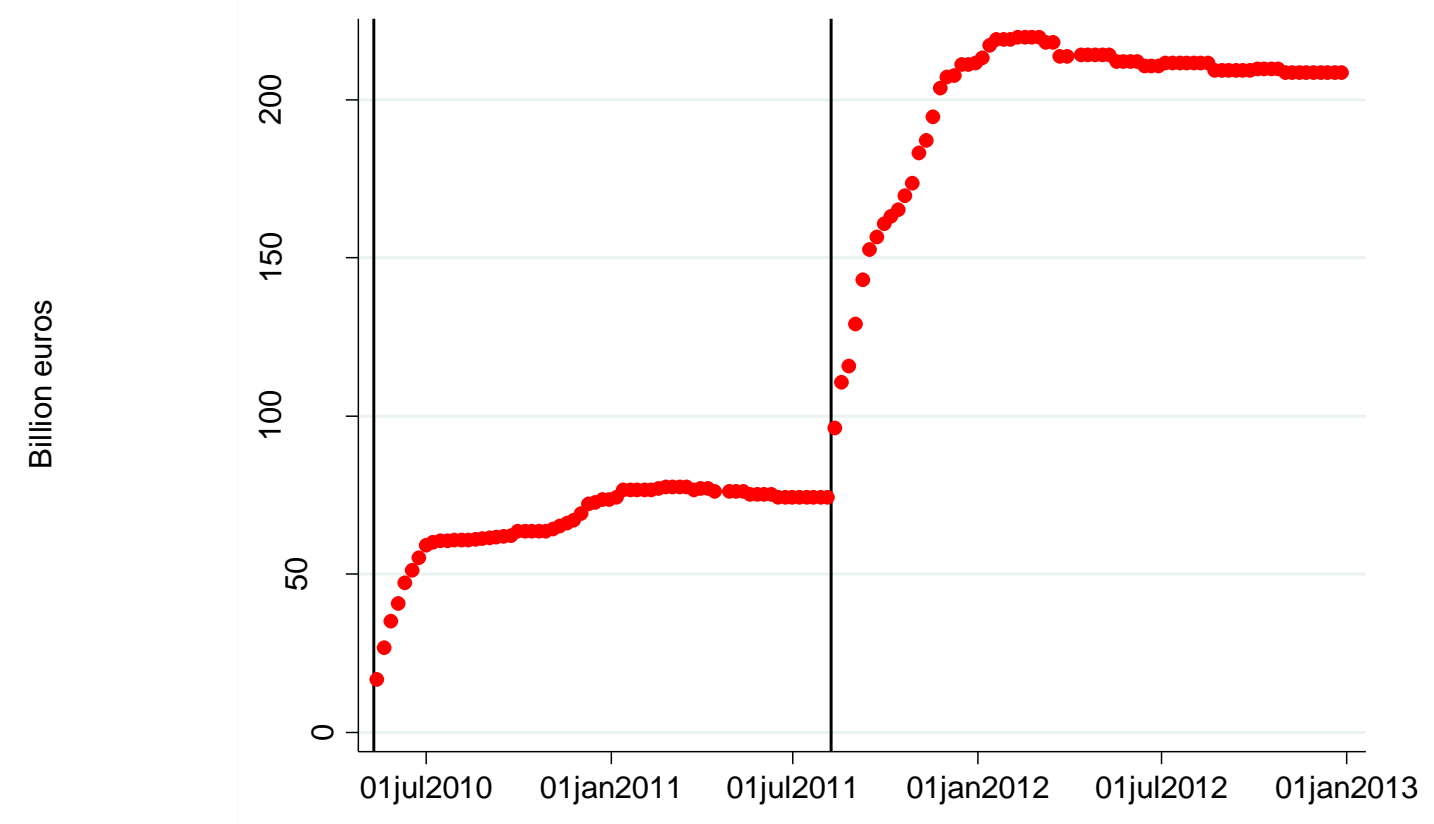

Source: ECB 
Figure 3. Bond yield decomposition for Italy

A. Italy, sovereign bond yields

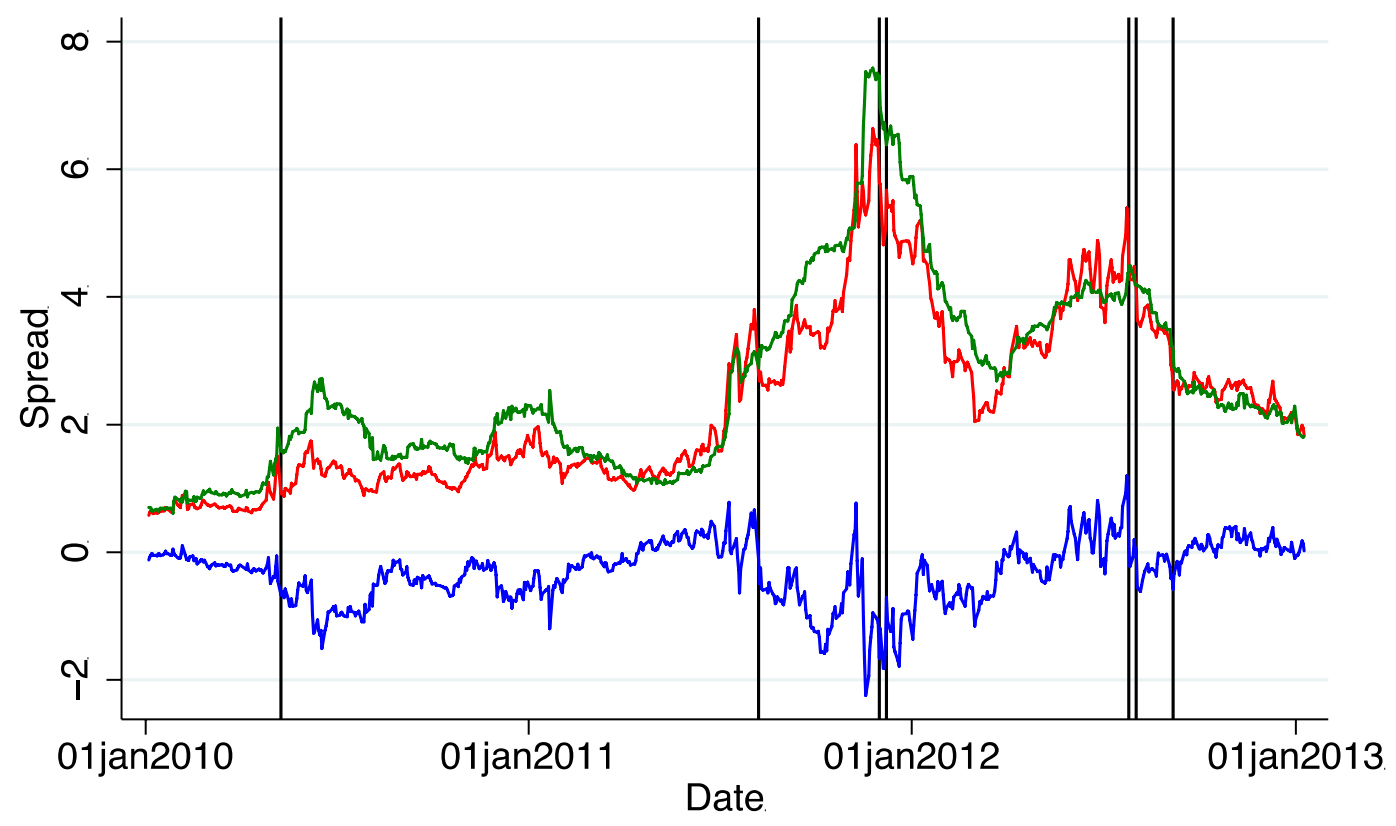

(1) Italy EUR domestic 2015 - EUR swap: To be decomp.

(2) Italy USD foreign 2015 - USD swap: Default

(1) - (2): Redenomination + Segmentation

B. Italy, corporate non-financial bond yields and CDS

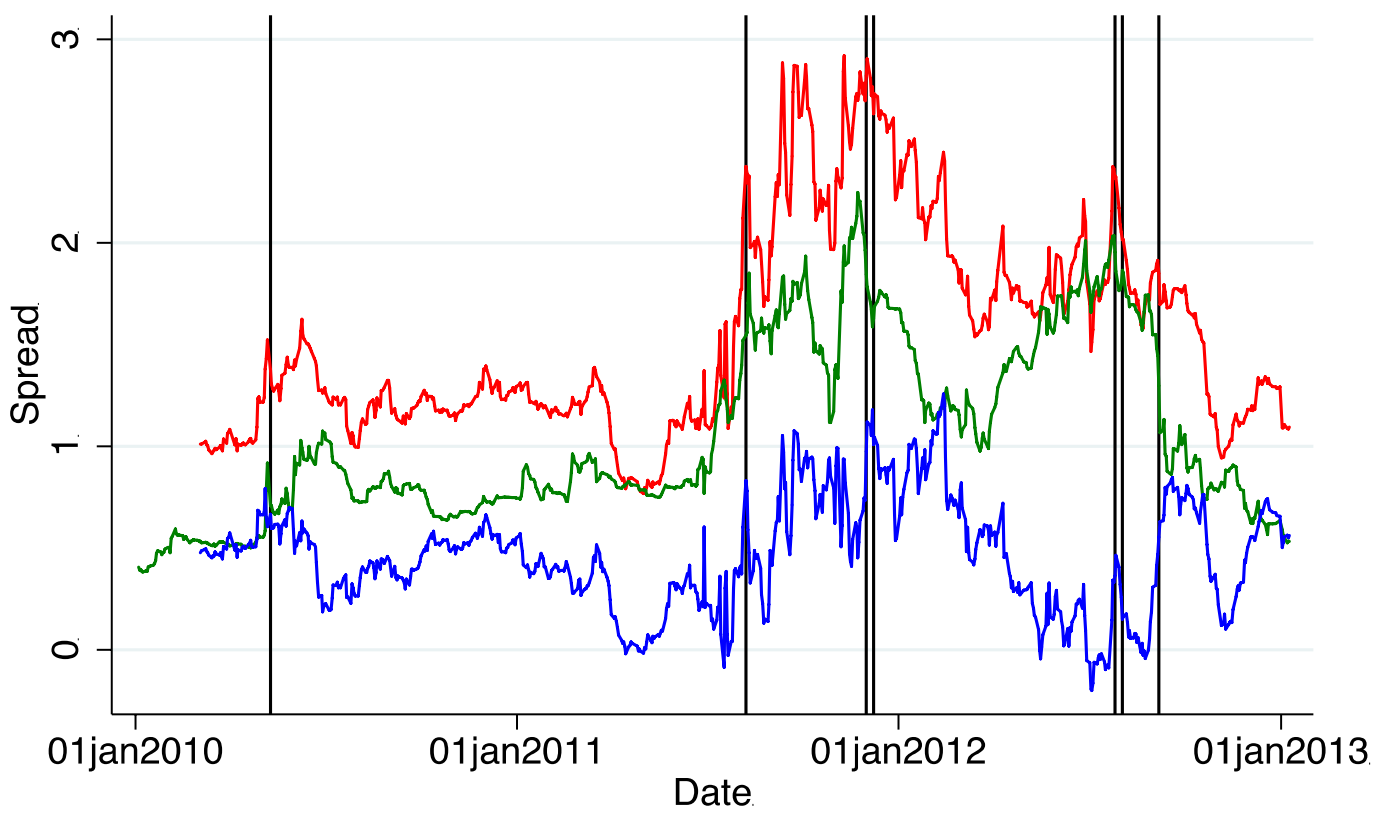

(1) ENI EUR domestic 2015 - EUR swap

(2) ENI CDS

(1) - (2): Redenomination + other CDS-bond basis comp. 
C. Italy, Kalman filtering results (baseline)

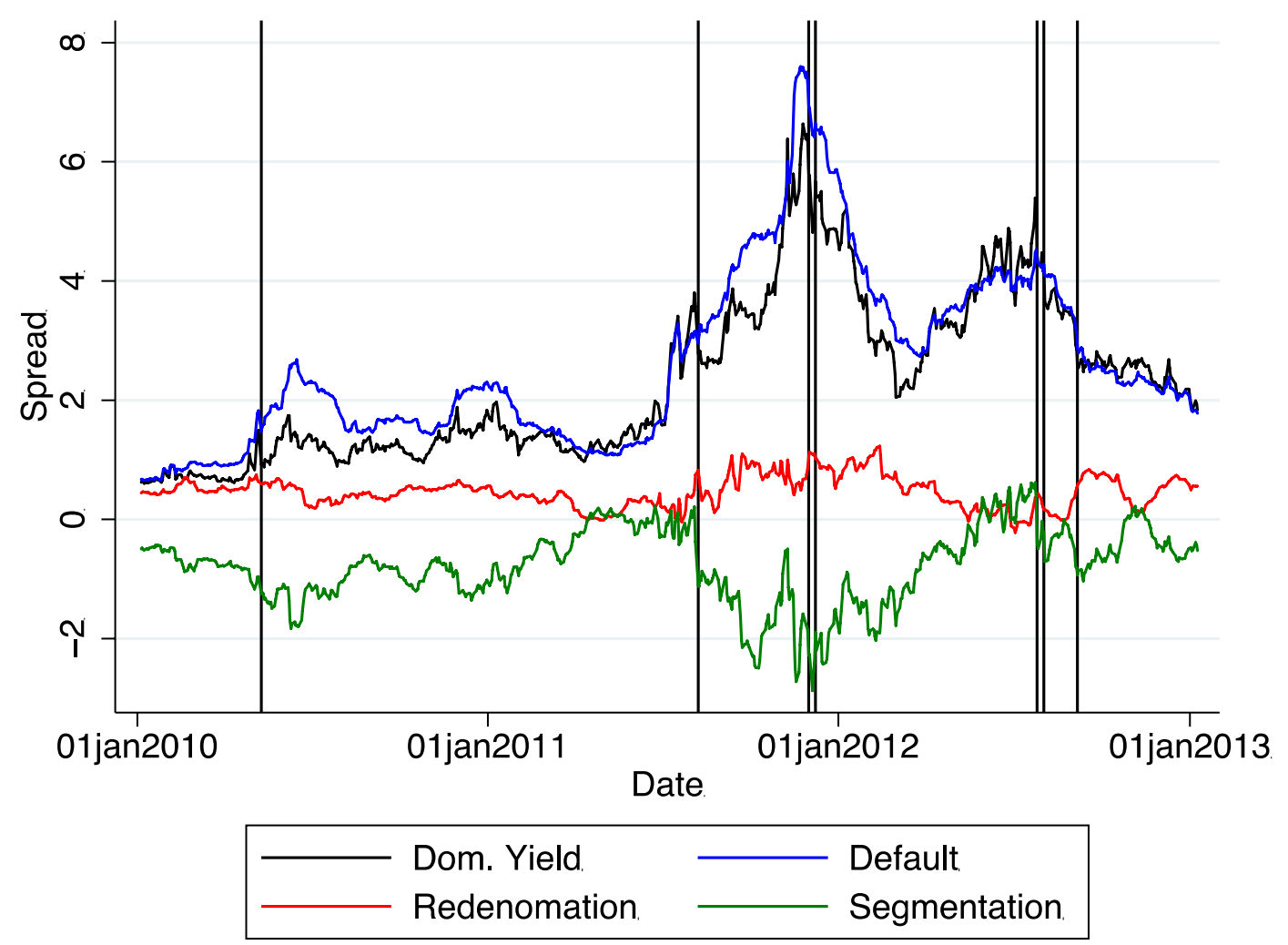


Figure 4. Bond yield decomposition for Spain

A. Spain, sovereign bond yields

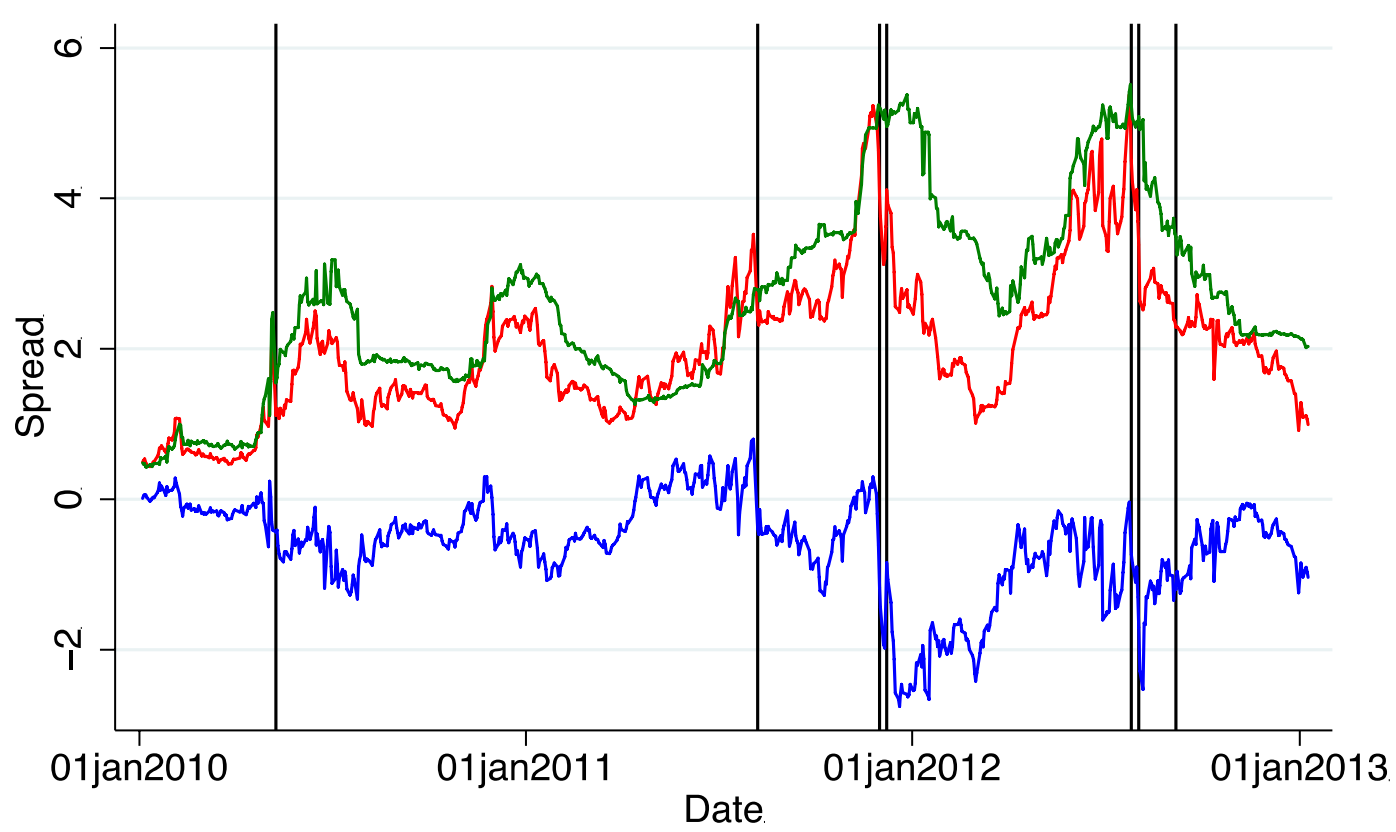

(1) Spain EUR domestic 2013 - EUR swap: To be decomp.

(2) Spain USD foreign 2013 - USD swap: Default

(1) - (2): Redenomination + Segmentation

B. Spain, corporate non-financial bond yields and CDS

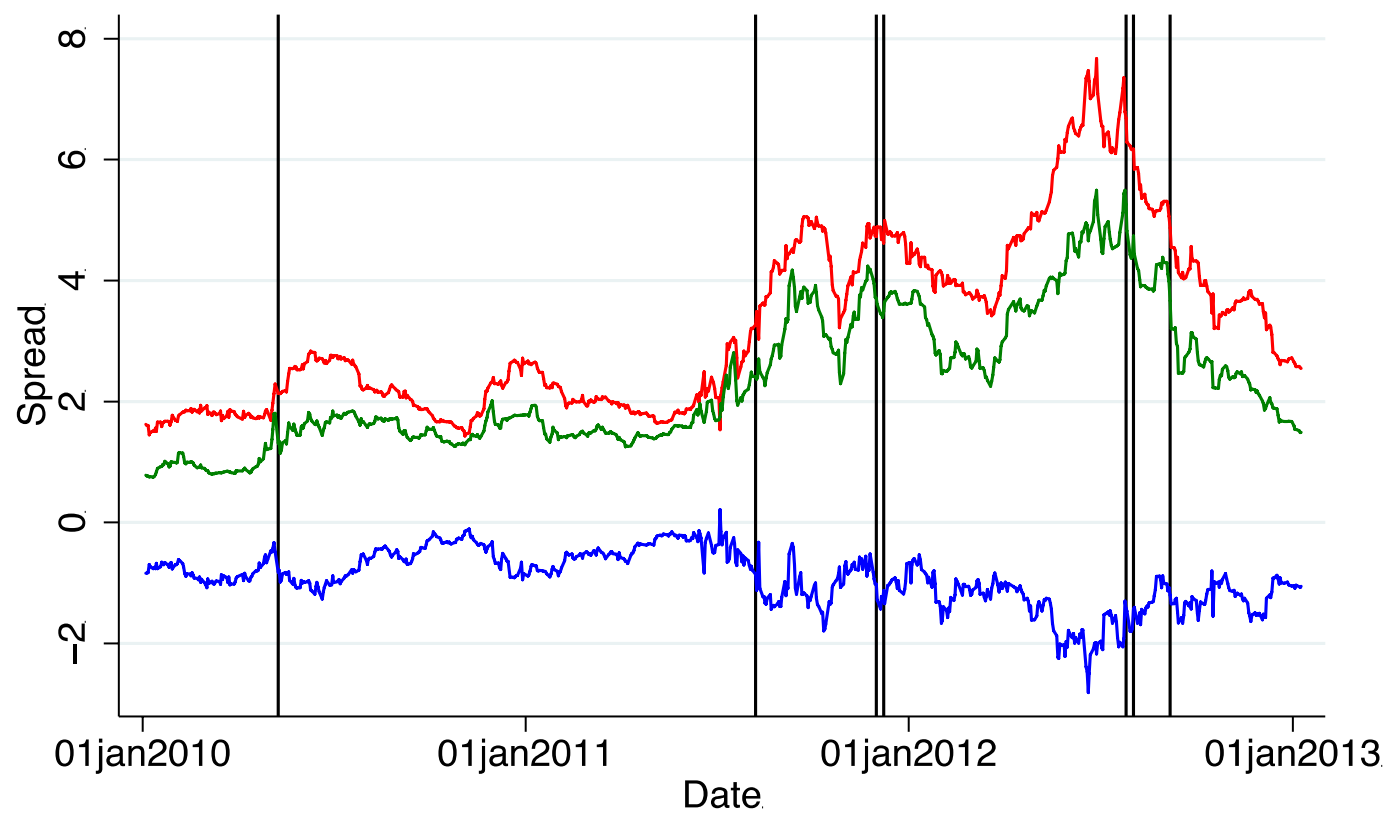

(1) Telefonica USD foreign 2016 - USD swap

(2) Telefonica CDS

(2) - (1): Redenomination + other CDS-bond basis comp. 
C. Spain, Kalman filtering results (baseline)
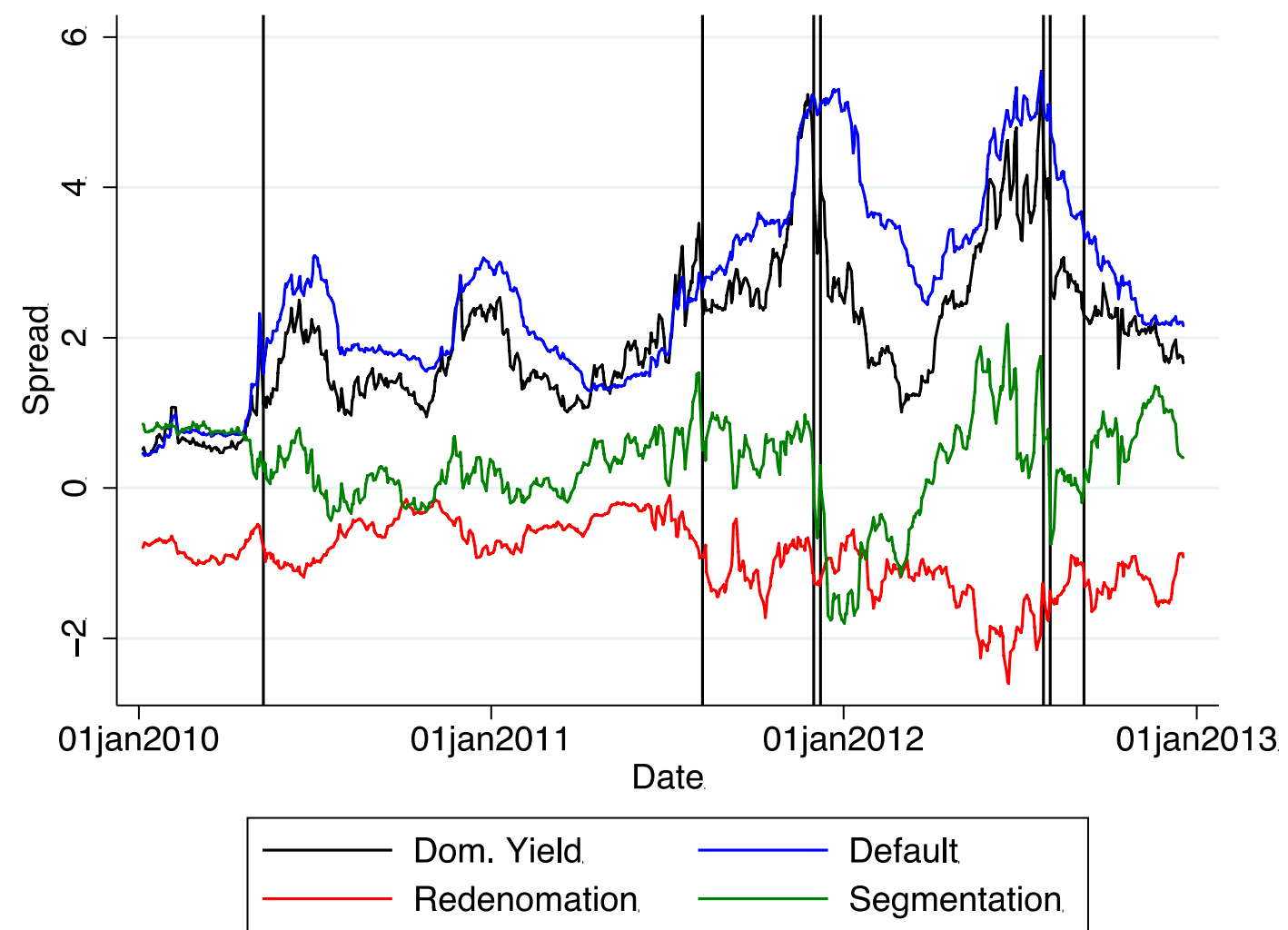

D. Spain, alternative measures incorporating redenomination risk premia

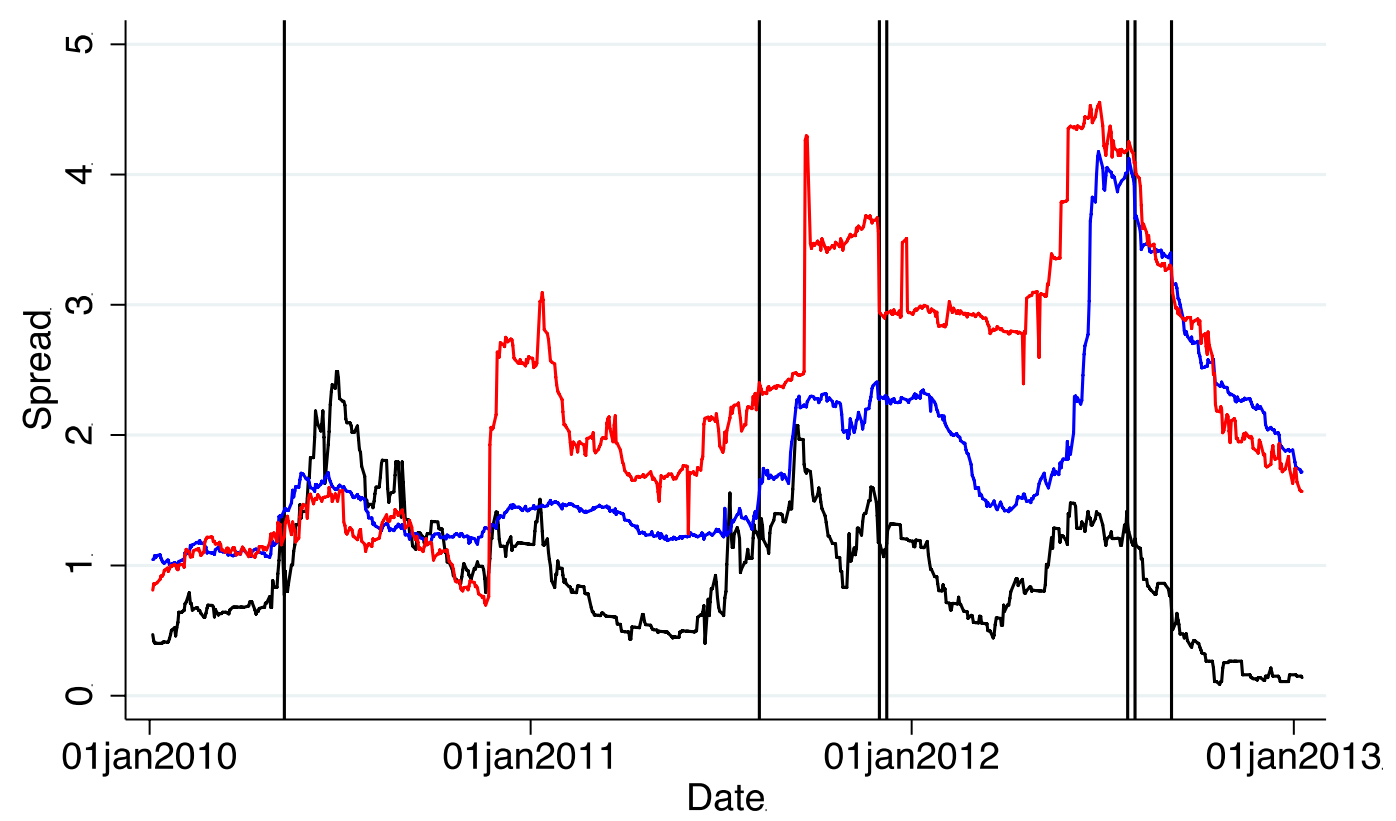

- Endesa 2013 CDS

Enagas EUR domestic 2015 - EUR swap Abertis EUR domestic 2013 - EUR swap 
Figure 5. Bond yield decomposition for Portugal

A. Portugal, sovereign bond yields

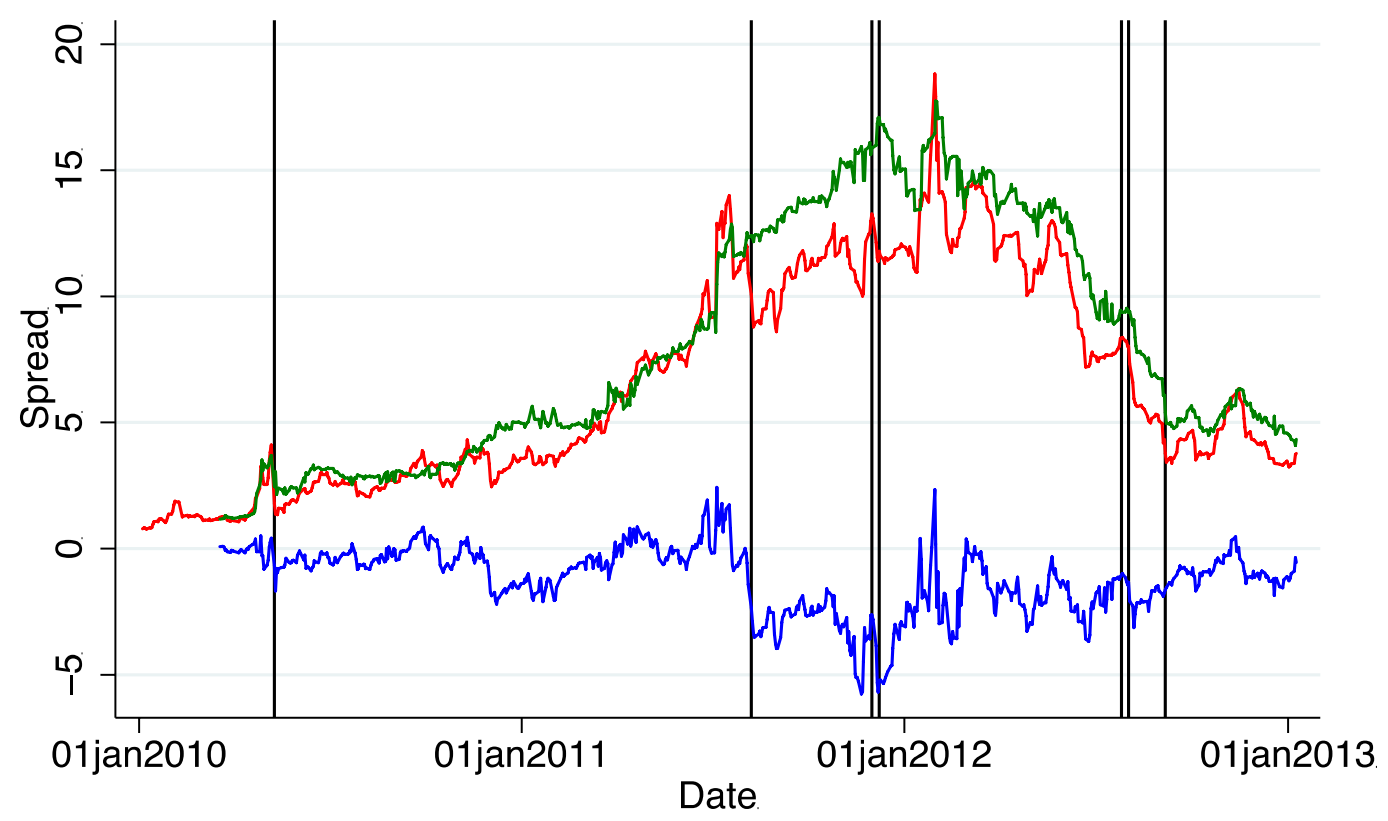

(1) Portugal EUR domestic 2015 - EUR swap: To be decomp.

(2) Portugal USD foreign 2015 - USD swap: Default

(1) - (2): Redenomination + Segmentation

B. Portugal, corporate non-financial bond yields and CDS

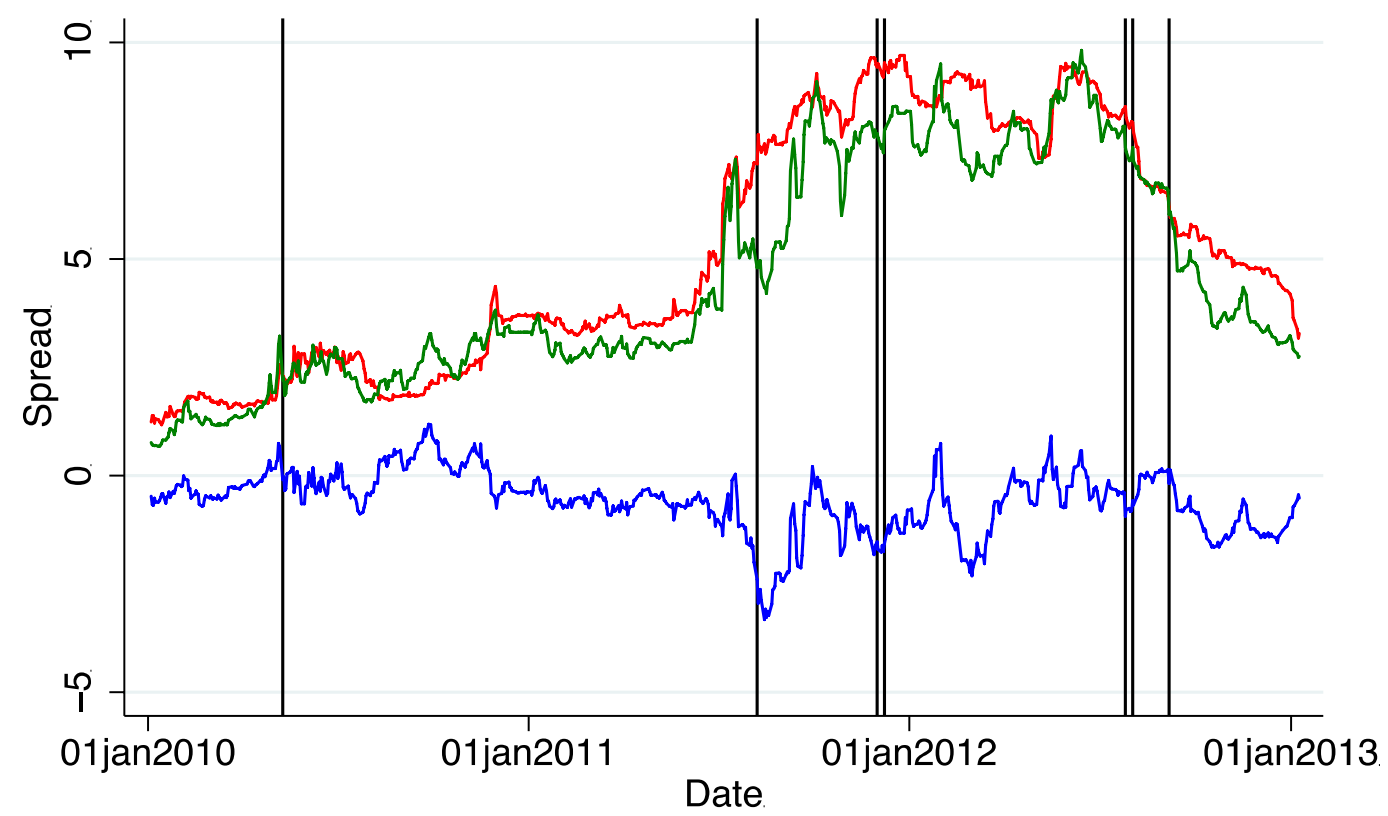

(1) EDP GBP foreign 2017 - GBP swap

(2) EDP CDS

(2) - (1): Redenomination + other CDS-bond basis comp. 
C. Portugal, Kalman filtering results (baseline)

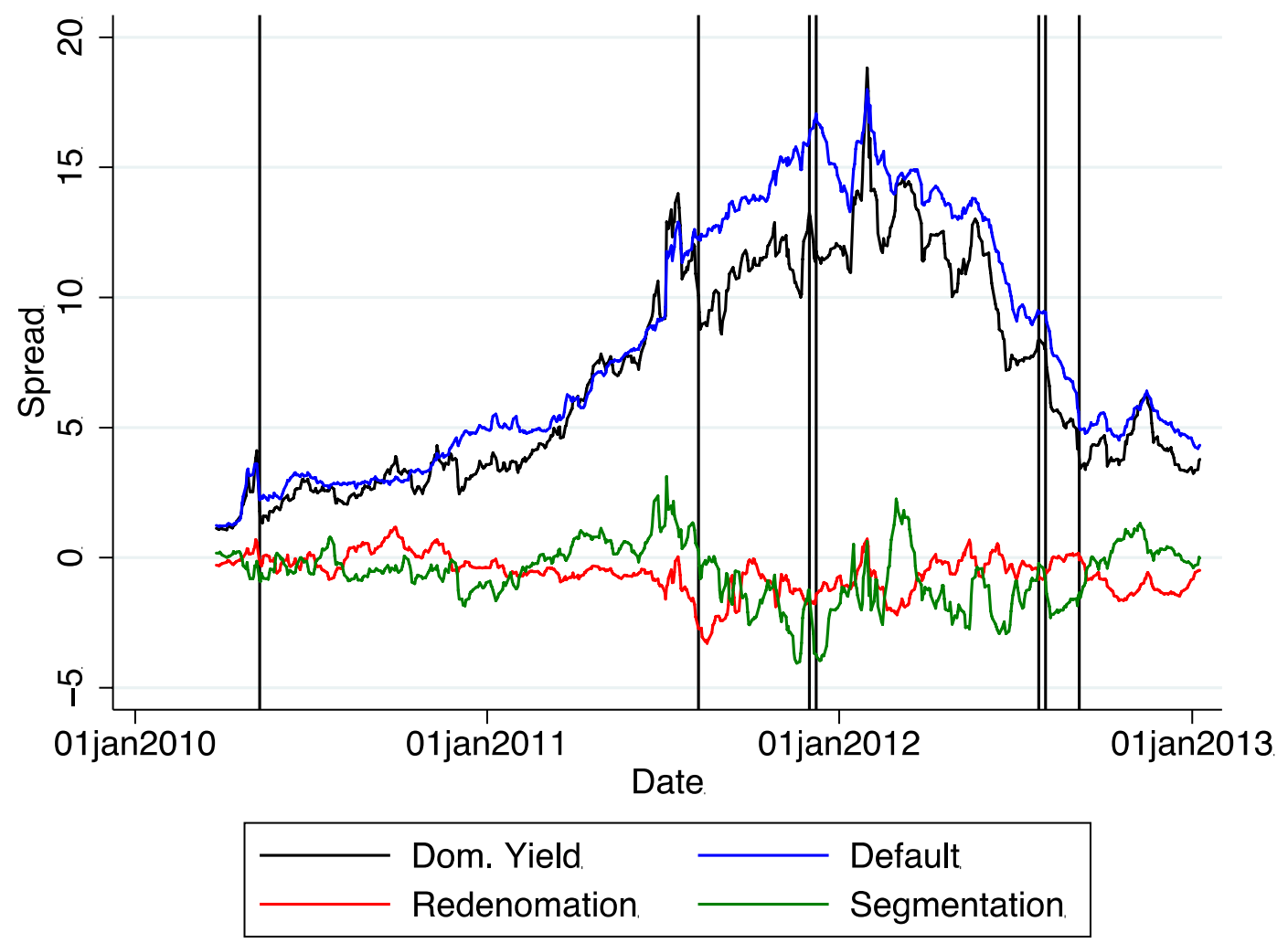


Figure 6. Bond yield decomposition for Greece around SMP dates

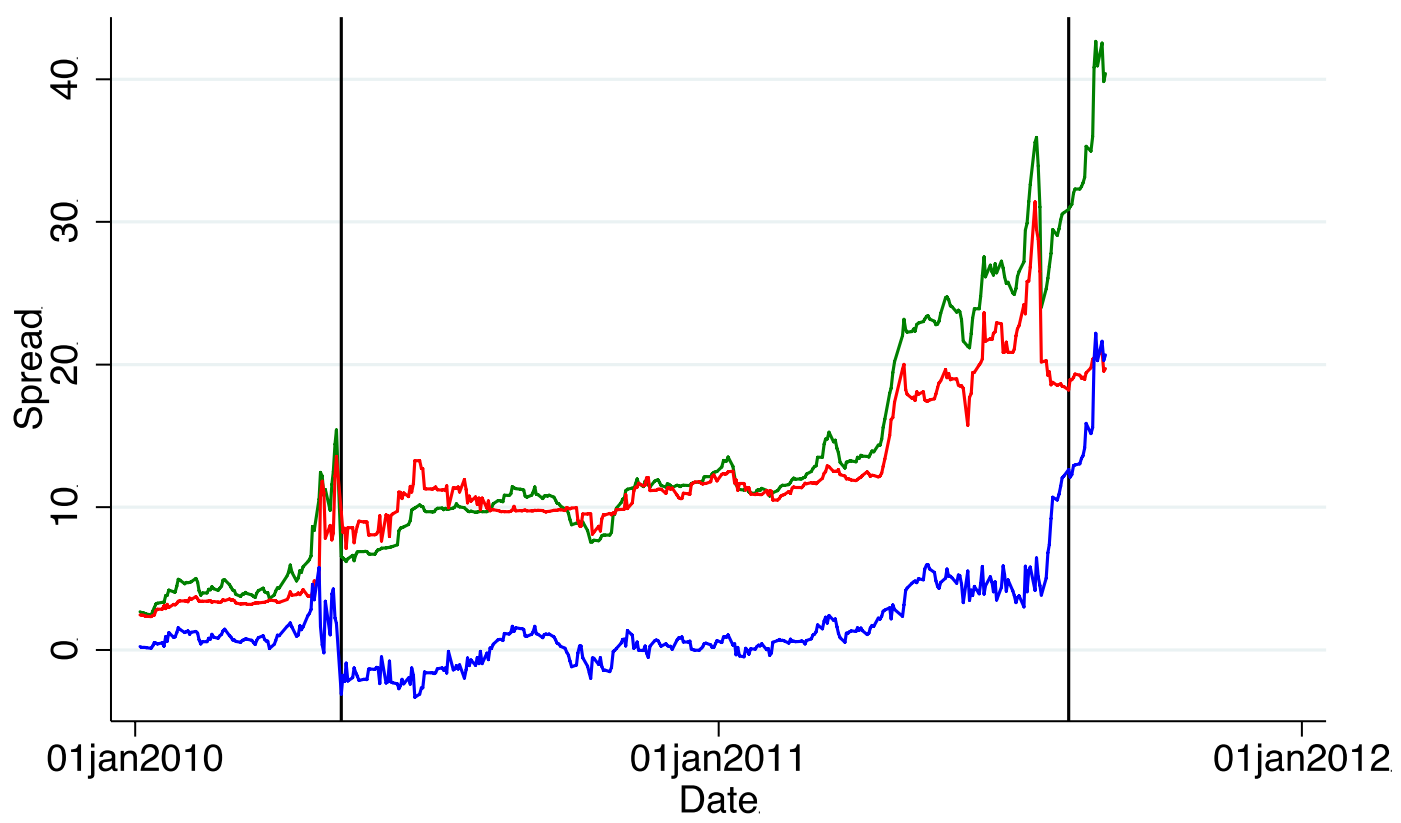

(1) Greece EUR domestic 2013 - EUR swap: To be decomp.

(2) Greece USD foreign 2013 - USD swap: Default

(1) - (2): Redenomination + Segmentation

Figure 7. 10-Year inflation swap rate (European CPI, ex-Tobacco).

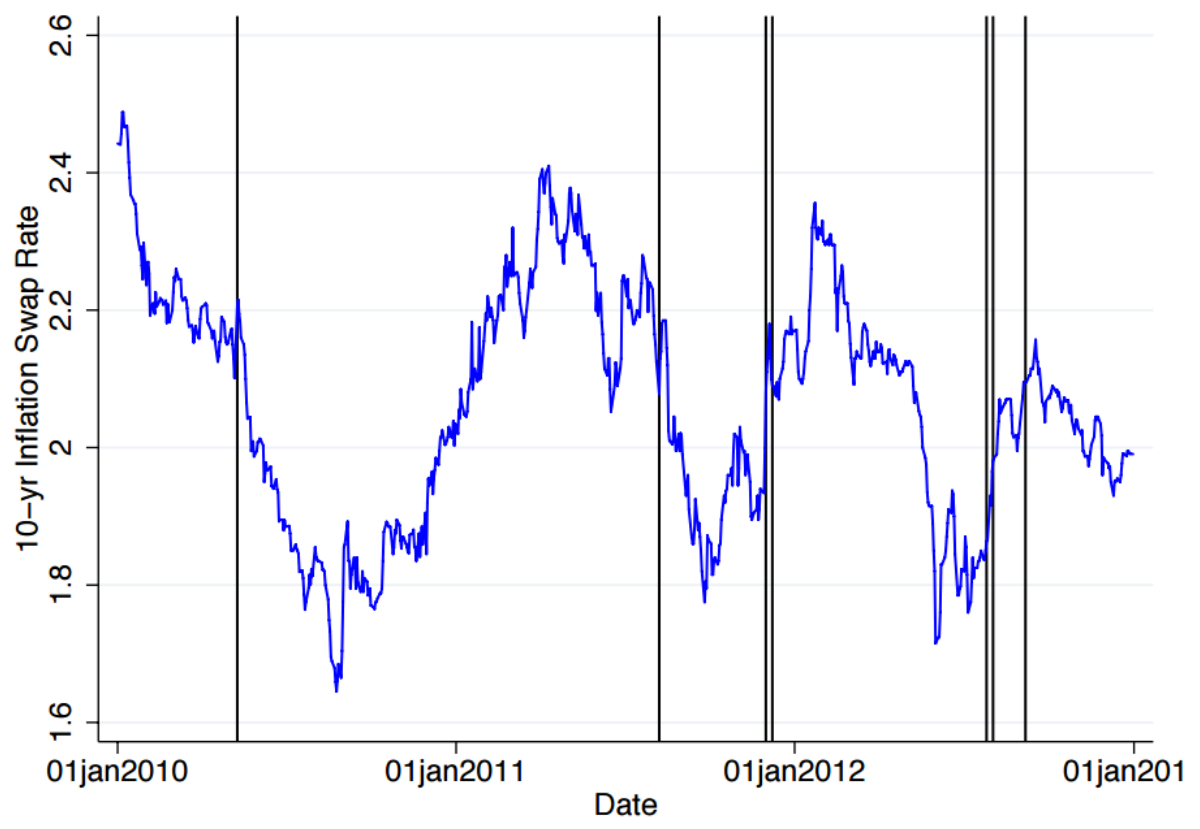

Source: Bloomberg. 
Table 1. Amounts of sovereign bond purchases due to ECB policies

Panel A. Securities markets programme, country distribution and average maturity of ECB holdings as of December 31 , 2012

\begin{tabular}{lcc}
\hline \hline Issuer country & ECB holdings (EUR billion), principal value & Average remaining maturity (years) \\
\hline Italy & 102.8 & 4.5 \\
Spain & 44.3 & 4.1 \\
Portugal & 22.8 & 3.9 \\
Ireland & 14.2 & 4.6 \\
Greece & 33.9 & 3.6 \\
\hline
\end{tabular}

Source: ECB press release, http://www.ecb.europa.eu/press/pr/date/2013/html/pr130221_1.en.html.

Note: Average maturities at purchase were up to 2.6 years higher than those stated above since purchases took place from May 2010 to February 2012. 
Panel B. Changes in resident bank holdings of GIIPS sovereign bonds during period of 3-year LTRO loans, Billions of Euros

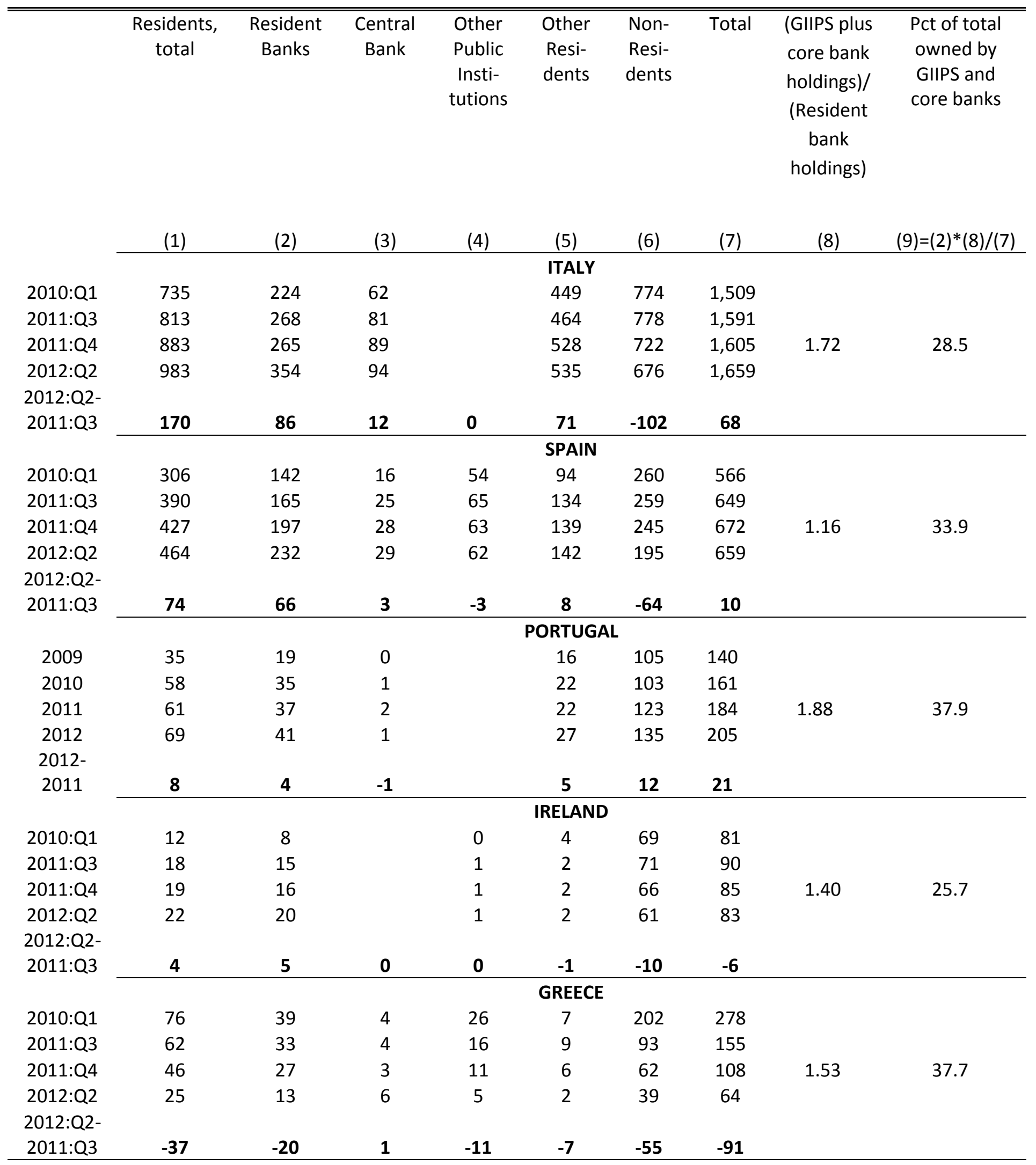

Sources: Column (1)-(7) are based on the Bruegel database of sovereign bond holdings. Holdings are at principal values for Italy, Portugal and Ireland and at market values for Spain. For Greece they are market value up to 2012:Q1 and principal value after that. Column (8) is based on EBA stress test results as of the end of 2011. 
Table 2. Identification

Panel A. The basic idea

\begin{tabular}{lccc}
\hline \hline & $\begin{array}{c}\text { Sovereign } \\
\text { default }\end{array}$ & $\begin{array}{c}\text { Redeno- } \\
\text { mination }\end{array}$ & $\begin{array}{c}\text { Domestic sovereign } \\
\text { segmentation }\end{array}$ \\
\hline Sovereign Yield - Swap & 1 & 1 & 1 \\
Sovereign USD Yield - USD Swap & 1 & 0 & 0 \\
A measure of redenomination risk from & 0 & 1 & 0 \\
corporate non-financial bonds & 0 & & \\
\hline
\end{tabular}

Panel B. Baseline implementation (method (i))

\begin{tabular}{lcccc}
\hline \hline & $\begin{array}{c}\text { Sovereign } \\
\text { default }\end{array}$ & $\begin{array}{c}\text { Corporate } \\
\text { default }\end{array}$ & $\begin{array}{c}\text { Redeno- } \\
\text { mination }\end{array}$ & $\begin{array}{c}\text { Domestic sovereign } \\
\text { segmentation }\end{array}$ \\
\hline Sovereign EUR Yield-EUR Swap & 1 & 0 & 1 & 1 \\
Sovereign USD Yield-USD Swap & 1 & 0 & 0 & 0 \\
ENI EUR Yield-EUR Swap & 0 & 1 & 1 & 0 \\
ENI CDS Rate & 0 & 1 & 0 & 0 \\
\hline & SPAIN & & & 1 \\
\hline Sovereign EUR Yield-EUR Swap & 1 & 0 & 1 & 0 \\
Sovereign USD Yield - USD Swap & 1 & 0 & 0 & 0 \\
Telefonica USD Yield - USD Swap & 0 & 1 & 0 & 0 \\
Telefonica CDS Rate & 0 & 1 & 1 & 1 \\
\hline Sovereign EUR Yield-EUR Swap & PORTUGAL & & & 0 \\
Sovereign USD Yield - USD Swap & 1 & 0 & 1 & 0 \\
EDP GBP Yield - GBP Swap & 0 & 0 & 0 & 0 \\
EDP CDS Rate & 0 & 1 & 0 & 1 \\
\hline
\end{tabular}

Panel C. Alternative implementation (method (ii))

\begin{tabular}{lcccc}
\hline \hline & $\begin{array}{c}\text { Sovereign } \\
\text { default }\end{array}$ & $\begin{array}{c}\text { Corporate } \\
\text { default }\end{array}$ & $\begin{array}{c}\text { Redeno- } \\
\text { mination }\end{array}$ & $\begin{array}{c}\text { Domestic sovereign } \\
\text { segmentation }\end{array}$ \\
\hline Sovereign EUR Yield-EUR Swap & 1 & 0 & 1 & 1 \\
Sovereign USD Yield - USD Swap & 1 & 0 & 0 & 0 \\
ENI EUR Yield-EUR Swap & 0 & 0 & 1 & 0 \\
\hline Sovereign EUR Yield-EUR Swap & SPAIN & & & 1 \\
Sovereign USD Yield - USD Swap & 1 & 0 & 1 & 0 \\
Endesa CDS & 1 & 0 & 0 & 0 \\
\hline
\end{tabular}


Panel D. Robustness check allowing for foreign segmentation (method (iii))

\begin{tabular}{|c|c|c|c|c|c|}
\hline & Sov. Default & $\begin{array}{c}\text { Corp. } \\
\text { Default }\end{array}$ & Redenom. & $\begin{array}{l}\text { Domestic } \\
\text { Sov. Seg. }\end{array}$ & $\begin{array}{c}\text { Foreign } \\
\text { Mkt. Seg. }\end{array}$ \\
\hline \multicolumn{6}{|c|}{ ITALY } \\
\hline Sovereign EUR Yield-EUR Swap & 1 & 0 & 1 & 1 & 0 \\
\hline Sovereign USD Yield - USD Swap & 1 & 0 & 0 & 0 & 1 \\
\hline ENI Yield - Swap & 0 & 1 & 1 & 0 & 0 \\
\hline ENI USD Yield - USD Swap & 0 & 1 & 0 & 0 & 1 \\
\hline ENI CDS Rate & 0 & 1 & 0 & 0 & 0 \\
\hline \multicolumn{6}{|c|}{ SPAIN } \\
\hline Sovereign EUR Yield-EUR Swap & 1 & 0 & 1 & 1 & 0 \\
\hline Sovereign USD Yield - USD Swap & 1 & 0 & 0 & 0 & 1 \\
\hline Telefonica USD Yield - USD Swap & 0 & 1 & 0 & 0 & 1 \\
\hline Telefonica CDS Rate & 0 & 1 & 1 & 0 & 0 \\
\hline Endesa CDS Rate & 0 & 0 & 1 & 0 & 0 \\
\hline
\end{tabular}




\begin{tabular}{|c|c|c|c|c|c|c|c|c|c|c|c|}
\hline \multirow[b]{2}{*}{ Policy } & \multirow[b]{2}{*}{ Ann. date } & $\begin{array}{l}\text { Avg. } \\
\text { yield }\end{array}$ & $6 \mathrm{mo}$ & $2 y r$ & $5 y r$ & $10 \mathrm{yr}$ & $\begin{array}{l}\text { Avg. } \\
\text { yield }\end{array}$ & $6 \mathrm{mo}$ & $2 y r$ & $5 y r$ & $10 \mathrm{yr}$ \\
\hline & & \multicolumn{5}{|c|}{ ITALY } & \multicolumn{5}{|c|}{ SPAIN } \\
\hline \multirow[t]{3}{*}{ SMP } & May 10, 2010 & -47 & -15 & -80 & -55 & -31 & -62 & ND & -87 & -75 & -51 \\
\hline & Aug 7, 2011 & -84 & -26 & -103 & -107 & -92 & -92 & ND & -115 & -112 & -98 \\
\hline & Total & -131 & -41 & -183 & -162 & -123 & -154 & ND & -202 & -187 & -149 \\
\hline \multirow[t]{4}{*}{ OMT } & Jul 26, 2012 & -72 & -48 & -116 & -77 & -48 & -89 & -69 & -113 & -89 & -63 \\
\hline & Aug 2, 2012 & -23 & -30 & -64 & -29 & 11 & -41 & -37 & -98 & -36 & 12 \\
\hline & Sep 6, 2012 & -31 & -15 & -21 & -42 & -46 & -54 & -7 & -37 & -67 & -78 \\
\hline & Total & -126 & -93 & -201 & -148 & -83 & -184 & -113 & -248 & -192 & -129 \\
\hline \multicolumn{12}{|l|}{ 3-year } \\
\hline \multirow[t]{3}{*}{ LTROs } & Dec 1, 2011 & -46 & -25 & -46 & -69 & -34 & -61 & -19 & -79 & -72 & -58 \\
\hline & Dec 8, 2011 & 35 & 10 & 30 & 47 & 35 & 30 & 36 & 28 & 34 & 32 \\
\hline & Total & -11 & -15 & -16 & -22 & 1 & -31 & 17 & -51 & -38 & -26 \\
\hline Policy & Ann. date & \multicolumn{5}{|c|}{ PORTUGAL } & \multicolumn{5}{|c|}{ IRELAND } \\
\hline \multirow[t]{3}{*}{ SMP } & May 10, 2010 & -219 & -92 & -378 & -268 & -176 & ND & ND & -289 & ND & -127 \\
\hline & Aug 7, 2011 & -120 & 0 & -172 & -188 & -52 & ND & ND & -281 & -102 & -49 \\
\hline & Total & -339 & -92 & -550 & -456 & -228 & ND & ND & -570 & ND & -176 \\
\hline \multirow[t]{4}{*}{ OMT } & Jul 26, 2012 & ND & 0 & 12 & -3 & -12 & ND & ND & -57 & -26 & ND \\
\hline & Aug 2, 2012 & ND & -5 & -21 & -42 & -8 & ND & ND & -13 & -7 & ND \\
\hline & Sep 6, 2012 & ND & 4 & -65 & -107 & -98 & ND & ND & 5 & -49 & ND \\
\hline & Total & ND & -1 & -74 & -152 & -118 & ND & ND & -65 & -82 & ND \\
\hline \multicolumn{12}{|l|}{ 3-year } \\
\hline \multirow[t]{3}{*}{ LTROs } & Dec 1, 2011 & -27 & 4 & -30 & -6 & -3 & ND & ND & -29 & -27 & $-N D$ \\
\hline & Dec 8, 2011 & 9 & 7 & 108 & 24 & 5 & ND & ND & 11 & -2 & ND \\
\hline & Total & -18 & 11 & 78 & 18 & 2 & ND & ND & -18 & -29 & ND \\
\hline Policy & Ann. date & \multicolumn{5}{|c|}{ GREECE } & & & & & \\
\hline \multirow[t]{3}{*}{ SMP } & May 10, 2010 & ND & -430 & -1123 & -698 & -500 & & & & & \\
\hline & Aug 7, 2011 & ND & ND & 93 & 8 & -3 & & & & & \\
\hline & Total & ND & ND & -1030 & -690 & -503 & & & & & \\
\hline \multirow[t]{4}{*}{ OMT } & Jul 26, 2012 & ND & ND & ND & ND & -78 & & & & & \\
\hline & Aug 2, 2012 & ND & ND & ND & ND & -67 & & & & & \\
\hline & Sep 6, 2012 & ND & ND & ND & ND & -36 & & & & & \\
\hline & Total & ND & ND & ND & ND & -181 & & & & & \\
\hline \multicolumn{12}{|l|}{ 3-year } \\
\hline \multirow[t]{3}{*}{ LTROs } & Dec 1, 2011 & ND & ND & 500 & 175 & -147 & & & & & \\
\hline & Dec 8, 2011 & ND & ND & 499 & 80 & 90 & & & & & \\
\hline & Total & ND & ND & 999 & 255 & -57 & & & & & \\
\hline
\end{tabular}

Sources: Avg. yields are from Barclay's indices. 6-month, 2, 5, and 10-year yields are mid-yields from Bloomberg. $N D=N o$ data. Bold indicates significance at the $5 \%$ level. 
Table 4. Impacts of policies on euro swap (EONIA OIS), 2-day changes

\begin{tabular}{|c|c|c|c|c|c|}
\hline Policy & Ann. date & & $2 y r$ & $5 y r$ & $10 \mathrm{yr}$ \\
\hline \multirow[t]{3}{*}{ SMP } & May 10, 2010 & & 1 & 5 & 15 \\
\hline & Aug 7, 2011 & & -21 & -15 & -16 \\
\hline & & Total & -20 & -10 & -1 \\
\hline \multirow[t]{4}{*}{ ОМт } & Jul 26, 2012 & & -9 & 4 & 12 \\
\hline & Aug 2, 2012 & & 4 & 6 & 5 \\
\hline & Sep 6, 2012 & & 3 & 6 & 8 \\
\hline & & Total & -2 & 16 & 25 \\
\hline \multirow[t]{3}{*}{ 3-year LTROs } & Dec 1, 2011 & & -4 & -5 & -6 \\
\hline & Dec 8, 2011 & & -1 & 6 & 2 \\
\hline & & Total & -5 & 1 & -4 \\
\hline
\end{tabular}

Source: Bloomberg

Note: Bold indicates significance at the 5 pct level.

Table 5. Weights on contemporaneous and lagged latent factors (up to lag 2), baseline specifications

\begin{tabular}{lcccc}
\hline \hline & \multicolumn{4}{c}{ ITALY $(q=2)$} \\
\hline & Lag 0 & Lag 1 & Lag 2 & \\
\cline { 2 - 5 } Sovereign Yield - Swap & 0.87 & 0.12 & 0.02 & \\
Sovereign USD Yield - USD Swap & 0.32 & 0.33 & 0.35 & \\
ENI Yield - Swap & 0.54 & 0.30 & 0.16 & \\
ENI CDS Rate & 0.61 & 0.27 & 0.12 & \\
\hline & \multicolumn{4}{c}{ SPAIN (q=3) } \\
\hline & Lag 0 & Lag 1 & Lag 2 & Lag 3 \\
\cline { 2 - 5 } Sovereign Yield - Swap & 0.81 & 0.16 & 0.03 & 0.01 \\
Sovereign USD Yield - USD Swap & 0.51 & 0.27 & 0.14 & 0.07 \\
Telefonica USD Yield - USD Swap & 0.42 & 0.28 & 0.18 & 0.12 \\
Telefonica CDS Rate & 0.67 & 0.23 & 0.08 & 0.03 \\
\hline & \multicolumn{3}{c}{ PORTUGAL $(q=2)$} \\
\hline & Lag 0 & Lag 1 & Lag 2 & \\
\cline { 2 - 5 } Sovereign Yield - Swap & 0.76 & 0.19 & 0.05 & \\
Sovereign USD Yield - USD Swap & 0.33 & 0.33 & 0.34 & \\
EDP GBP Yield - GBP Swap & 0.50 & 0.31 & 0.19 & \\
EDP CDS Rate & 0.65 & 0.25 & 0.10 & \\
\hline
\end{tabular}




\begin{tabular}{|c|c|c|c|c|c|c|c|c|c|c|}
\hline \multicolumn{11}{|c|}{ ITALY } \\
\hline \multirow[b]{2}{*}{ Policy } & \multirow[b]{2}{*}{ Ann. date } & \multicolumn{3}{|c|}{ Default Risk Premium } & \multicolumn{3}{|c|}{ Redenomination Risk Premium } & \multicolumn{3}{|c|}{ Domestic Sovereign Segmentation } \\
\hline & & (i) & (ii) & (iii) & (i) & (ii) & (iii) & (i) & (ii) & (iii) \\
\hline \multirow[t]{3}{*}{ SMP } & May 10, 2010 & -28 & -25 & -41 & -4 & -23 & -5 & -27 & -11 & -14 \\
\hline & Aug 7, 2011 & -7 & -6 & -11 & -5 & 0 & -5 & -76 & -81 & -73 \\
\hline & Total & -35 & -31 & -51 & -9 & -24 & -9 & -103 & -92 & -87 \\
\hline \multirow[t]{4}{*}{ OMT } & Jul 26, 2012 & -22 & -22 & -41 & 7 & -17 & 6 & -79 & -55 & -60 \\
\hline & Aug 2, 2012 & -8 & -9 & -11 & -4 & -8 & -5 & -49 & -44 & -43 \\
\hline & Sep 6, 2012 & -35 & -29 & -65 & 8 & -22 & 9 & -5 & 20 & 24 \\
\hline & Total & -64 & -60 & -117 & 11 & -48 & 10 & -133 & -79 & -79 \\
\hline \multirow[t]{3}{*}{ 3-year LTROs } & Dec 1, 2011 & -45 & -44 & -57 & 28 & 14 & 28 & -42 & -29 & -30 \\
\hline & Dec 8, 2011 & 11 & 9 & 17 & -9 & 0 & -9 & 22 & 14 & 17 \\
\hline & Total & -34 & -35 & -40 & 19 & 14 & 19 & -20 & -15 & -14 \\
\hline \multicolumn{11}{|c|}{ SPAIN } \\
\hline & & \multicolumn{3}{|c|}{ Default Risk Premium } & \multicolumn{3}{|c|}{ Redenomination Risk Premium } & \multicolumn{3}{|c|}{ Domestic Sovereign Segmentation } \\
\hline Policy & Ann. date & (i) & (ii) & (iii) & (i) & (ii) & (iii) & (i) & (ii) & (iii) \\
\hline \multirow[t]{3}{*}{ SMP } & May 10, 2010 & -47 & -44 & -32 & -21 & -36 & -36 & -14 & -3 & -14 \\
\hline & Aug 7, 2011 & -17 & -17 & -12 & 1 & -5 & -3 & -72 & -70 & -73 \\
\hline & Total & -64 & -61 & -44 & -20 & -41 & -39 & -86 & -73 & -87 \\
\hline \multirow[t]{4}{*}{ OMT } & Jul 26, 2012 & -40 & -36 & -39 & -24 & -17 & -23 & -22 & -32 & -24 \\
\hline & Aug 2, 2012 & -36 & -31 & -12 & 17 & -6 & -5 & -93 & -76 & -94 \\
\hline & Sep 6, 2012 & -20 & -15 & -24 & -31 & -19 & -28 & 37 & 25 & 39 \\
\hline & Total & -96 & -81 & -76 & -37 & -42 & -56 & -78 & -83 & -79 \\
\hline \multirow[t]{3}{*}{ 3-year LTROs } & Dec 1, 2011 & -6 & -6 & -18 & -14 & -4 & -1 & -67 & -78 & -68 \\
\hline & Dec 8, 2011 & 7 & 4 & 1 & 12 & 14 & 19 & -2 & -5 & -3 \\
\hline & Total & 1 & -1 & -17 & -3 & 8 & 18 & -69 & -83 & -72 \\
\hline
\end{tabular}




\section{PORTUGAL}

\begin{tabular}{|c|c|c|c|c|}
\hline & & Default Risk Premium & Redenomination Risk Premium & Domestic Sovereign Segmentation \\
\hline Policy & Ann. date & (i) & (i) & (i) \\
\hline \multirow[t]{3}{*}{ SMP } & May 10, 2010 & -126 & -72 & -79 \\
\hline & Aug 7, 2011 & -2 & -46 & -88 \\
\hline & Total & -128 & -118 & -167 \\
\hline \multirow[t]{4}{*}{ OMT } & Jul 26, 2012 & -7 & -25 & 25 \\
\hline & Aug 2, 2012 & -37 & 13 & -67 \\
\hline & Sep 6, 2012 & -71 & -15 & -9 \\
\hline & Total & -116 & -28 & -51 \\
\hline \multirow[t]{3}{*}{ 3-year LTROs } & Dec 1, 2011 & 50 & -6 & -57 \\
\hline & Dec 8, 2011 & -10 & 40 & -15 \\
\hline & Total & 40 & 34 & -71 \\
\hline
\end{tabular}

Note: Bold indicates significance at the 5 pct level. 
Table 7. Impact of ECB policies on stock market values, by policy and country, 2-day changes Panel A. All stocks

\begin{tabular}{|c|c|c|c|c|c|c|c|c|c|c|c|c|c|}
\hline \multirow[b]{2}{*}{ Policy } & \multirow[b]{2}{*}{ Ann. Date } & \multicolumn{5}{|c|}{ GIIPS } & \multicolumn{6}{|c|}{ Core } & \multirow[t]{2}{*}{ EMU } \\
\hline & & Italy & Spain & Portugal & Ireland & Greece & $\begin{array}{c}\text { Ger- } \\
\text { many }\end{array}$ & France & $\begin{array}{c}\text { Nether- } \\
\text { lands }\end{array}$ & $\begin{array}{l}\text { Bel- } \\
\text { gium }\end{array}$ & Austria & Finland & \\
\hline & & & \multicolumn{11}{|c|}{ 2-day returns around event dates } \\
\hline \multirow[t]{3}{*}{ SMP } & May 10, 2010 & 9.06 & 9.39 & 7.77 & 6.03 & 5.93 & 5.12 & 7.82 & 6.32 & 7.70 & 6.89 & 6.22 & 7.55 \\
\hline & Aug 7, 2011 & -2.28 & -2.64 & -4.14 & -1.96 & -5.21 & -5.55 & -3.37 & -3.98 & -1.63 & -5.63 & -0.17 & -3.48 \\
\hline & Total & 6.78 & 6.75 & 3.63 & 4.07 & 0.72 & -0.43 & 4.45 & 2.34 & 6.07 & 1.26 & 6.05 & 4.07 \\
\hline \multirow[t]{4}{*}{ OMT } & Jul 26, 2012 & 7.28 & 9.12 & 4.00 & 2.58 & -0.65 & 3.71 & 5.55 & 3.66 & 3.73 & 3.16 & 4.88 & 7.19 \\
\hline & Aug 2, 2012 & 1.59 & 1.04 & -0.15 & 1.10 & -0.15 & 1.29 & 1.45 & 0.37 & 0.58 & 0.78 & 0.77 & 1.52 \\
\hline & Sep 6, 2012 & 4.74 & 4.56 & 3.89 & 2.05 & 2.63 & 3.11 & 2.92 & 2.52 & 1.40 & 3.34 & 4.14 & 4.83 \\
\hline & Total & 13.61 & 14.72 & 7.74 & 5.73 & 1.83 & 8.11 & 9.92 & 6.55 & 5.71 & 7.28 & 9.79 & 13.54 \\
\hline 3-year & Dec 1, 2011 & 1.11 & 1.17 & 0.66 & -1.02 & 1.35 & 0.15 & 0.14 & 0.57 & 0.41 & 0.39 & -1.33 & 0.13 \\
\hline \multirow[t]{2}{*}{ LTROs } & Dec 8, 2011 & -0.96 & -0.09 & -1.09 & -0.52 & -0.87 & -0.63 & -0.34 & -0.40 & -0.83 & -1.12 & -2.43 & -0.76 \\
\hline & Total & 0.15 & 1.08 & -0.43 & -1.54 & 0.48 & -0.48 & -0.20 & 0.17 & -0.42 & -0.73 & -3.76 & -0.63 \\
\hline \multicolumn{14}{|c|}{ Panel B. Financial sector stocks } \\
\hline & & \multicolumn{5}{|c|}{ GIIPS } & \multicolumn{6}{|c|}{ Core } & EMU \\
\hline \multirow[t]{2}{*}{ Policy } & Ann. Date & Italy & Spain & Portugal & Ireland & Greece & $\begin{array}{l}\text { Ger- } \\
\text { many }\end{array}$ & France & $\begin{array}{c}\text { Nether- } \\
\text { lands }\end{array}$ & $\begin{array}{l}\text { Bel- } \\
\text { gium }\end{array}$ & Austria & Finland & \\
\hline & & & \multicolumn{11}{|c|}{ 2-day returns around event dates } \\
\hline \multirow[t]{3}{*}{ SMP } & May 10, 2010 & 13.27 & 14.95 & 10.12 & 14.59 & 7.97 & 6.13 & 14.04 & 10.54 & 11.22 & 9.41 & 8.33 & 11.92 \\
\hline & Aug 7, 2011 & -0.21 & -2.02 & -0.81 & 5.96 & -2.46 & -5.83 & -3.42 & -5.01 & -1.80 & -6.93 & -0.26 & -3.14 \\
\hline & Total & 13.06 & 12.93 & 9.31 & 20.55 & 5.51 & 0.30 & 10.62 & 5.53 & 9.42 & 2.48 & 8.07 & 8.78 \\
\hline \multirow[t]{4}{*}{ OMT } & Jul 26, 2012 & 8.59 & 14.72 & 3.09 & 10.36 & -0.45 & 5.64 & 7.94 & 3.90 & 3.54 & 4.77 & 4.17 & 9.71 \\
\hline & Aug 2, 2012 & 0.69 & 0.60 & -1.73 & 0.09 & -1.84 & 1.24 & 1.80 & 1.00 & 0.43 & 1.46 & 1.70 & 1.45 \\
\hline & Sep 6, 2012 & 8.24 & 5.75 & 16.28 & 9.77 & 4.57 & 5.09 & 6.60 & 4.87 & 4.40 & 4.40 & 2.62 & 7.52 \\
\hline & Total & 17.52 & 21.07 & 17.64 & 20.22 & 2.28 & 11.97 & 16.34 & 9.77 & 8.37 & 10.63 & 8.49 & 18.68 \\
\hline 3-year & Dec 1, 2011 & 2.78 & 2.40 & 8.43 & -3.79 & -0.41 & 2.36 & 2.92 & 2.73 & 1.97 & 3.29 & 0.45 & 2.28 \\
\hline \multirow[t]{2}{*}{ LTROs } & Dec 8, 2011 & -1.33 & -0.07 & -0.87 & -0.10 & -1.53 & -0.66 & -1.50 & -1.83 & -1.16 & -2.79 & -0.77 & -1.25 \\
\hline & Total & 1.45 & 2.33 & 7.56 & -3.89 & -1.94 & 1.70 & 1.42 & 0.90 & 0.81 & 0.50 & -0.32 & 1.03 \\
\hline
\end{tabular}




\begin{tabular}{|c|c|c|c|c|c|c|c|c|c|c|c|c|c|}
\hline \multirow[b]{2}{*}{ Policy } & \multirow[b]{2}{*}{ Ann. date } & \multicolumn{5}{|c|}{ GIIPS } & \multicolumn{6}{|c|}{ Core } & \multirow[t]{2}{*}{ EMU } \\
\hline & & Italy & Spain & Portugal & Ireland & Greece & $\begin{array}{l}\text { Ger- } \\
\text { many }\end{array}$ & France & $\begin{array}{c}\text { Nether- } \\
\text { lands }\end{array}$ & $\begin{array}{l}\text { Bel- } \\
\text { gium }\end{array}$ & Austria & Finland & \\
\hline & & & \multicolumn{10}{|c|}{ 2-day returns around event dates } & \\
\hline \multirow[t]{3}{*}{ SMP } & May 10, 2010 & 7.09 & 6.55 & 7.29 & 5.26 & 4.69 & 4.91 & 6.44 & 5.08 & 6.29 & 5.00 & 5.98 & 6.26 \\
\hline & Aug 7, 2011 & -3.04 & -2.93 & -4.60 & -2.48 & -6.63 & -5.51 & -3.36 & -3.63 & -1.58 & -4.69 & -0.16 & -3.57 \\
\hline & Total & 4.05 & 3.62 & 2.69 & 2.78 & -1.94 & -0.60 & 3.08 & 1.45 & 4.71 & 0.31 & 5.82 & 2.69 \\
\hline \multirow[t]{4}{*}{ OMT } & Jul 26, 2012 & 6.89 & 6.69 & 4.06 & 1.95 & -0.69 & 3.42 & 5.16 & 3.59 & 3.77 & 2.21 & 5.01 & 6.65 \\
\hline & Aug 2, 2012 & 1.87 & 1.20 & 0.00 & 1.20 & 0.27 & 1.30 & 1.39 & 0.31 & 0.61 & 0.37 & 0.60 & 1.54 \\
\hline & Sep 6, 2012 & 3.52 & 3.96 & 2.62 & 1.47 & 2.17 & 2.79 & 2.25 & 1.88 & 0.82 & 2.70 & 4.43 & 4.20 \\
\hline & Total & 12.28 & 11.85 & 6.68 & 4.62 & 1.75 & 7.51 & 8.80 & 5.78 & 5.20 & 5.28 & 10.04 & 12.39 \\
\hline 3-year & $\operatorname{Dec} 1,2011$ & 0.55 & 0.60 & 0.11 & -0.82 & 1.82 & -0.21 & -0.34 & -0.11 & 0.07 & -1.11 & -1.60 & -0.37 \\
\hline \multirow[t]{2}{*}{ LTROs } & Dec 8, 2011 & -0.83 & -0.10 & -1.11 & -0.55 & -0.70 & -0.62 & -0.12 & 0.06 & -0.75 & -0.18 & -2.69 & -0.65 \\
\hline & Total & -0.28 & 0.50 & -1.00 & -1.37 & 1.12 & -0.83 & -0.46 & -0.05 & -0.68 & -1.29 & -4.29 & -1.02 \\
\hline
\end{tabular}

Source: Datastream indices downloaded from Datastream. Bold indicates significance at the $5 \%$ level. 
Table 8. How much of bank stock returns can be explained by gains on GIIPS sovereign bond holdings?

\begin{tabular}{|c|c|c|c|c|c|c|c|c|c|c|c|c|c|}
\hline Policy & Ann. date & $\begin{array}{l}\text { Market cap- } \\
\text { weighted } \\
\text { average bank } \\
\text { stock return }\end{array}$ & \multicolumn{5}{|c|}{ GIIPS } & \multicolumn{6}{|c|}{ Core } \\
\hline \multirow{6}{*}{ SMP } & & & \multicolumn{11}{|c|}{ 2-day returns around event dates } \\
\hline & May 10, 2010 & Actual & 14.81 & 16.01 & 4.47 & 16.22 & 11.96 & 9.58 & 16.68 & 17.90 & 14.63 & 10.76 & 15.00 \\
\hline & Aug 7, 2011 & Actual & 1.20 & -5.34 & -1.05 & 3.50 & -0.60 & -5.88 & -3.93 & -6.11 & -2.87 & -11.47 & -1.84 \\
\hline & & Implied & 3.40 & 1.54 & 5.63 & 0.44 & -0.21 & 5.68 & 1.65 & 0.82 & 12.23 & 0.01 & 0.05 \\
\hline & Total & Actual & 16.01 & 10.67 & 3.42 & 19.72 & 11.36 & 3.70 & 12.75 & 11.79 & 11.76 & -0.71 & 13.16 \\
\hline & & Implied & 4.56 & 2.34 & 18.20 & 4.55 & 55.22 & 16.26 & 3.77 & 1.97 & 24.40 & 0.03 & 0.12 \\
\hline \multirow[t]{7}{*}{ OMT } & Jul 26, 2012 & Actual & 12.27 & 16.10 & -0.08 & 1.39 & -0.04 & 7.01 & 13.56 & 8.93 & 8.44 & 4.25 & 5.87 \\
\hline & Aug 2, 2012 & Actual & 0.18 & 1.51 & -0.57 & -0.37 & -0.33 & 1.22 & 1.70 & 0.63 & -2.82 & 0.53 & -1.55 \\
\hline & & Implied & 0.17 & 0.04 & 1.35 & 0.04 & 3.13 & 0.50 & 0.16 & 0.09 & 0.47 & 0.00 & 0.00 \\
\hline & Sep 6, 2012 & Actual & 9.83 & 6.42 & 8.26 & 4.34 & 6.53 & 12.63 & 11.40 & 9.77 & 13.44 & 9.65 & 6.03 \\
\hline & & Implied & 1.70 & 0.91 & 6.64 & 0.20 & 1.55 & 2.99 & 1.07 & 0.53 & 11.53 & 0.01 & 0.00 \\
\hline & Total & Actual & 22.28 & 24.03 & 7.61 & 5.36 & 6.16 & 20.86 & 26.66 & 19.33 & 19.06 & 14.43 & 10.35 \\
\hline & & Implied & 5.13 & 2.11 & 9.99 & 0.40 & 9.47 & 7.16 & 3.00 & 1.38 & 25.18 & 0.02 & 0.01 \\
\hline \multirow{5}{*}{$\begin{array}{l}\text { 3-year } \\
\text { LTROs }\end{array}$} & Dec 1, 2011 & Actual & 1.51 & 2.78 & 0.78 & -0.53 & -0.17 & 5.37 & 4.96 & 5.40 & 17.71 & 1.05 & 3.30 \\
\hline & & Implied & 1.76 & 0.98 & 1.61 & 0.11 & -0.55 & 3.57 & 1.12 & 0.52 & 18.69 & 0.00 & 0.00 \\
\hline & Dec 8, 2011 & Actual & -2.45 & 0.09 & -0.88 & 5.71 & -0.30 & -1.45 & -2.23 & -2.36 & -1.41 & -6.46 & -2.49 \\
\hline & & Implied & -1.52 & -0.52 & -3.80 & 0.00 & -3.93 & -2.85 & -1.02 & -0.39 & -12.65 & -0.01 & -0.01 \\
\hline & & Implied & 0.24 & 0.46 & -2.19 & 0.11 & -4.48 & 0.72 & 0.10 & 0.13 & 6.04 & -0.01 & -0.01 \\
\hline
\end{tabular}

Note: The table is based on banks that both provided data to the EBA's 2011 stress tests and were publicly traded on the particular event date and have data in Compustat Global Security Daily. The number of banks varies between 31 and 35 across event dates. We calculate implied stock returns based on reported holdings of each of the GIIPS countries' sovereign bonds by maturity bucket, along with our documented yield changes by maturity from Table 3 . In case of missing values in Table 3, we do the following: If the 6-month yield is missing, use the 2-year yield. If the 5-year yield is missing, use the average of the 2 and 10 -year yields. If the 10-year yield is missing, use the 5-year yield, and for Greece use the 10-year yield for all maturities when only the 10 -year yield is available. 
Table 9. Impacts of policies on corporate bond yields, by policy and country, 2-day changes

\begin{tabular}{|c|c|c|c|c|c|c|}
\hline Policy & Ann. date & Italy & Spain & Portugal & Ireland & Greece \\
\hline \multirow[t]{3}{*}{ SMP } & May 10, 2010 & -3 & -16 & -43 & ND & ND \\
\hline & Aug 7, 2011 & 15 & 16 & -20 & ND & ND \\
\hline & Total & 12 & 0 & -63 & ND & ND \\
\hline \multirow[t]{4}{*}{ OMT } & Jul 26, 2012 & -4 & -26 & ND & ND & ND \\
\hline & Aug 2, 2012 & -6 & -7 & ND & ND & ND \\
\hline & Sep 6, 2012 & -30 & -58 & ND & ND & ND \\
\hline & Total & -40 & -91 & ND & ND & ND \\
\hline 3-year & Dec 1, 2011 & -40 & -30 & -35 & ND & ND \\
\hline \multirow[t]{2}{*}{ LTROs } & Dec 8, 2011 & 12 & 7 & 28 & ND & ND \\
\hline & Total & -28 & -23 & -7 & ND & ND \\
\hline
\end{tabular}

Source: Barclay's indices. Bold indicates significance at the $5 \%$ level.

Table 10. Increase in total market value of GIIPS sovereign bonds and EMU stocks on SMP and OMT event dates, 2-day changes

\begin{tabular}{lccccccc}
\hline \hline & Italy & Spain & Portugal & Ireland & Greece & GIIPS total & EMU \\
\cline { 2 - 8 } & \multicolumn{7}{c}{ Stocks } \\
\cline { 2 - 8 } SMP & 27.5 & 28.5 & 1.9 & 1.9 & 1.3 & 61.1 & 167.7 \\
OMT & 44.7 & 49.7 & 3.0 & 2.6 & 0.4 & 100.4 & 601.0 \\
Total & 72.2 & 78.1 & 5.0 & 4.5 & 1.7 & 161.5 & 768.6 \\
\hline
\end{tabular}

\begin{tabular}{|c|c|c|c|c|c|c|c|}
\hline & Italy & Spain & Portugal & Ireland & Greece & GIIPS total & $\begin{array}{c}\text { Italy, } \\
\text { Spain, } \\
\text { Portugal }\end{array}$ \\
\hline & \multicolumn{6}{|c|}{ Bonds (government and corporate) } & $\begin{array}{l}\text { Corp } \\
\text { bonds }\end{array}$ \\
\hline SMP & 63.6 & 39.9 & 14.0 & 9.7 & 41.6 & 168.8 & 0.0 \\
\hline OMT & 62.1 & 43.0 & 0.0 & 6.3 & 0.0 & 111.4 & 4.5 \\
\hline Total & 125.7 & 82.9 & 14.0 & 16.0 & 41.6 & 280.2 & 4.5 \\
\hline
\end{tabular}

Sources:

Stocks: For each SMP and OMT announcement date we calculate the two-day change in stock market value for a given country (or the EMU overall) using the product of the corresponding 2-day stock return from Table 7, Panel A and the market value at the end of the day prior to the particular announcement (both returns and market value data are obtained from Datastream and are for Datastream's stock indices).

Bonds: For each SMP and OMT announcement date we calculate the two-day change in bond market value for a given country based on the total market value of Barclay's country level bond index (obtained from Datastream). These bond indices cover both government and corporate bonds. For Italy, Spain and Portugal separate sub-indices covering only corporate bonds are used in the last column. Bond market coverage is very low for Greece for the second SMP date and all OMT dates and for Portugal for all OMT dates (index coverage drops discretely on a date prior to these dates). 
Table A.1. Input data for Kalman filter

For bond yields, whenever possible, we use Bloomberg CBBT or BGN mid-yields. We choose between CBBT and BGN based on which of the two series has lower serial correlation of yield changes (measured by the $\mathrm{R}^{2}$ in a regression of yield changes on five own lags). For the Portugal USD bond, neither CBBT nor BGN is available for an extended period and we fill in BVAL, Bloomberg's estimate of market value calculated using proprietary methods. We use Bloomberg data when available and Datastream otherwise.

\begin{tabular}{lcc}
\hline \hline & ITALY & \\
\hline Sovereign EUR Yield & Italy $3.75 \% 08 / 01 / 2015$ & Bloomberg (CBBT) \\
Sovereign USD Yield & Italy $4.50 \% 01 / 21 / 2015$ & Bloomberg (BGN) \\
ENI EUR Yield & ENI SpA $4.00 \%$ 06/29/2015 (BGN) \\
ENI CDS Rate & EUR Senior CDS & Bloomberg ENIIM CDS EUR SR \\
ENI USD Yield & ENI Finance 6.125\% 12/17/2018 & Bloomberg (BGN) \\
\hline & SPAIN & Bloomberg (CBBT) \\
\hline Sovereign EUR Yield & Spain 4.20\% 07/30/2013 & Bloomberg (BGN) \\
Sovereign USD Yield & Spain 3.625\% 06/17/2013 & Bloomberg (CBBT) \\
Telefonica USD Yield & Telefonica Emisiones 6.421\% 06/20/2016 & Bloomberg TELEFOA CDS EUR SR \\
Telefonica CDS Rate & EUR Senior CDS & Datastream ELE1EAC, ELE2EAC, ... \\
Endesa CDS Rate & EUR Senior CDS & \\
\hline Sovereign EUR Yield & PORTUGAL & Bloomberg (CBBT) \\
Sovereign USD Yield & Portugal 3.35\% 10/15/2015 & Bloomberg (CBBT) \\
EDP GBP Yield & Portugal 3.50\% 03/25/2015 & Bloomberg (CBBT) \\
EDP CDS Rate & EDP Finance 6.625\% 08/09/2017 & Datastream EDP1EAC, EDP2EAC, \\
\hline
\end{tabular}

*Adjusted by difference in CDS rates matched to 2015 domestic and the 2018 USD bond.

Table A.2. Other data series used in figures

\begin{tabular}{lcc}
\hline \hline & SPAIN & \\
\hline $\begin{array}{l}\text { Enagas EUR Yield } \\
\text { Abertis EUR Yield }\end{array}$ & Enagas 4.375\% 07/06/2015 & Bloomberg (BGN) \\
& Abertis 4.95\% 08/08/2013 & Datastream 36606T \\
\hline Sovereign EUR Yield & GREECE & \\
Sovereign USD Yield & Greece 4.00\% 08/20/2013 & Bloomberg (BGN) \\
\hline
\end{tabular}


Table A.3. Liquidity-risk related movements in yield spreads

\begin{tabular}{|c|c|c|c|c|c|c|c|c|}
\hline \multirow[b]{2}{*}{ Policy } & \multirow[b]{2}{*}{ Ann. date } & & \multicolumn{2}{|c|}{ Italy } & \multicolumn{2}{|c|}{ Spain } & \multicolumn{2}{|c|}{ Portugal } \\
\hline & & & Domestic & Foreign & Domestic & Foreign & Domestic & Foreign \\
\hline \multirow[t]{3}{*}{ SMP } & May 10, 2010 & & -7 & -7 & -6 & -8 & -24 & -10 \\
\hline & Aug 7, 2011 & & -5 & -5 & -4 & -5 & -17 & -7 \\
\hline & & Total & -11 & -11 & -10 & -13 & -41 & -16 \\
\hline \multirow[t]{4}{*}{ OMT } & Jul 26, 2012 & & -3 & -3 & -3 & -4 & -11 & -5 \\
\hline & Aug 2, 2012 & & -2 & -2 & -2 & -2 & -7 & -3 \\
\hline & Sep 6, 2012 & & -1 & -1 & -1 & -1 & -3 & -1 \\
\hline & & Total & -6 & -6 & -5 & -7 & -22 & -9 \\
\hline 3-year & Dec 1, 2011 & & 4 & 4 & 3 & 5 & 14 & 6 \\
\hline \multirow[t]{2}{*}{ LTROs } & Dec 8, 2011 & & -3 & -3 & -2 & -3 & -9 & -4 \\
\hline & & Total & 1 & 1 & 1 & 1 & 5 & 2 \\
\hline
\end{tabular}

Note: We estimate the liquidity beta by regressing daily sovereign yield changes (using the same bond yield data samples as in Panel A of Figures 3, 4, and 5) on daily changes in the KfW-Bund spread (based on Germany sovereign bonds and $\mathrm{KfW}$ bonds, both maturing on 07/04/2015, with data from Bloomberg) and the change corresponding sovereign CDS rate (including two lags of each variable, with the liquidity beta as the three KfW-Bund coefficients). The liquidity-risk related impact on yield movements on day $t$ is calculated as the liquidity beta times the change in the KfWBund spread on day $t$, which we then regress on event dummies. The coefficients on the event-window dummies are shown in the table. Bold indicates significance at the $5 \%$ level. 